\title{
Cellular and Molecular Mechanisms of Vitamin D Deficiency in Aging and Alzheimer's Disease
}

\section{Shiler Khaledi, Shamseddin Ahmadi*}

Department of Biological Sciences, Faculty of Sciences, University of Kurdistan, Sanandaj, Iran

\section{Article Info:}

\section{ABSTRACT}

Introduction: Vitamin D is implicated in regulation of various biological processes, including calcium homeostasis, neurogenesis, synaptic plasticity, the immune system, and inflammation. Nowadays, most part of the population worldwide is affected by vitamin D deficiency. The decreases in different factors, including the cutaneous thickness, the sun exposure time, muscle mass, kidney efficiency, and sex steroids in aged people (especially women), as well as malnutrition cause vitamin D deficiency, which in turn may act as an important risk factor for Alzheimer's disease (AD). There is a reciprocal relationship between amyloid $\beta(A \beta)$ as a core factor that initiates the onset and progression of AD and the increases in calcium $\left(\mathrm{Ca}^{2+}\right)$ levels in neurons. Vitamin D via genomic functions, including either a decreasing expression of L-type $\mathrm{Ca}^{2+}$ channels or increasing expression of $\mathrm{Ca}^{2+}$ pumps, $\mathrm{Na}^{+} / \mathrm{Ca}^{2+}$ exchanger, as well as $\mathrm{Ca}^{2+}$ buffers, has the main role in $\mathrm{Ca}^{2+}$ homeostasis. Therefore, vitamin $\mathrm{D}$ through influencing intracellular $\mathrm{Ca}^{2+}$ can prevent $\mathrm{A} \beta$ production and inhibit its subsequent neurotoxic effects. It also indirectly controls neuroinflammation and oxidative stress via influencing intracellular $\mathrm{Ca}^{2+}$ levels and thereby postpone either onset or progress of AD. Conclusion: Taken together, this review shows that vitamin D can control the normal process of physiological aging, and

\section{Key words:}

1. Cholecalciferol

2. Amyloid beta-Peptides

3. Calcium Signaling

4. Memory Disorders its deficiency may initiate AD by disrupting different cellular and molecular mechanisms in the neural system. Therefore, vitamin D as a food and drug supplement along with other effective drugs may have a preventive role in the induction and progression of AD.

*Corresponding Author: Shamseddin Ahmadi

E-mail:sh.ahmadi@uok.ac.ir 
مكانيسمهاى سلولى و مولكولى كمبود ويتامين D در ييرى و بيمارى آلزايمر

\author{
شيلر خالدى، شمسالدين احمدى"
}

كروه علوم زيستى، دانشكده علوم، دانشَاه كردستان، سنندج، ايران

\title{
اطلاعات مقاله:
}

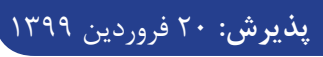

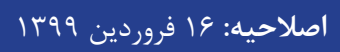

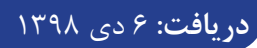

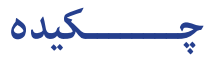

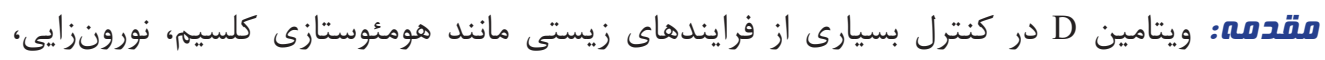

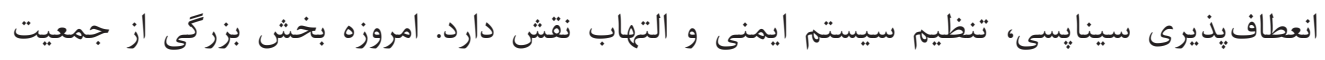

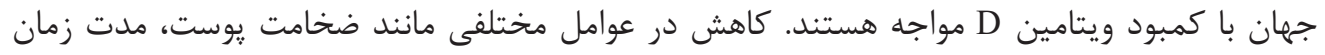

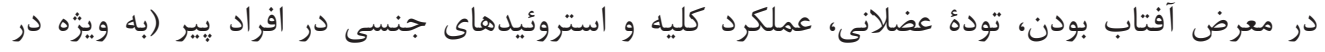

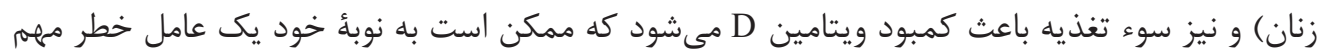

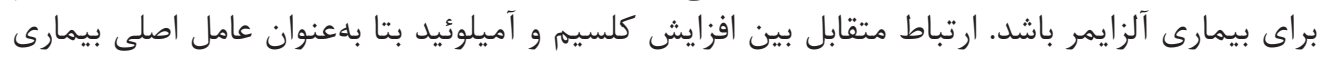

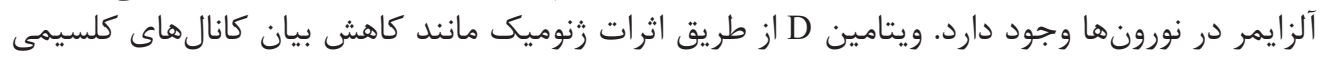

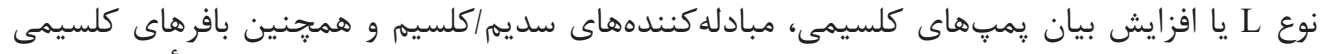

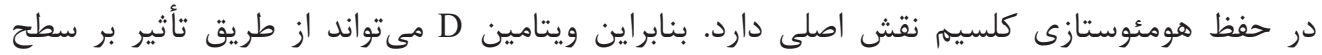

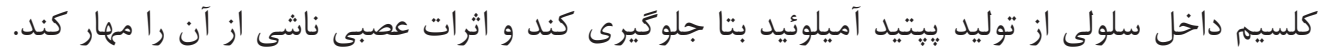

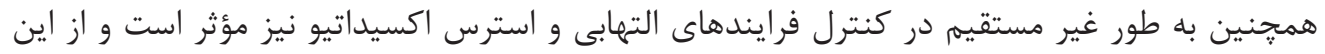

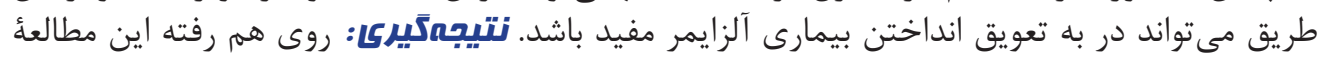

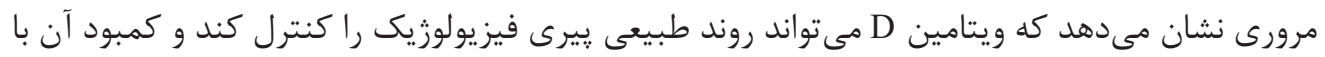

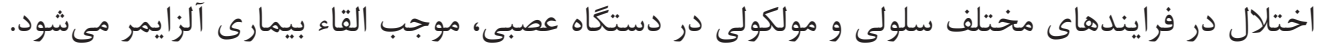

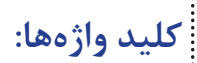

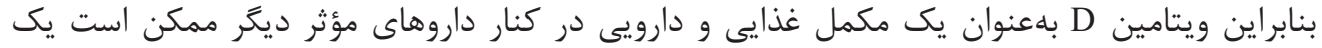

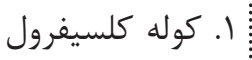

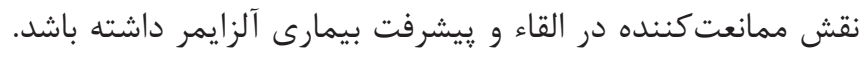

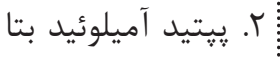

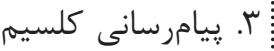

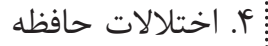




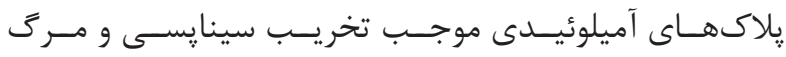

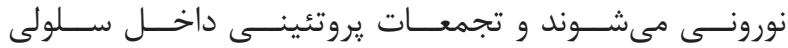

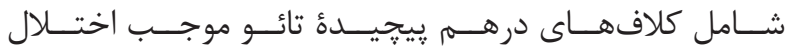

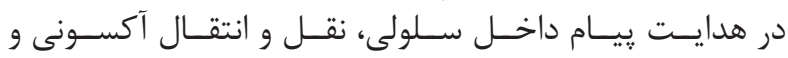

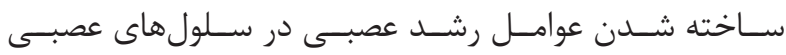

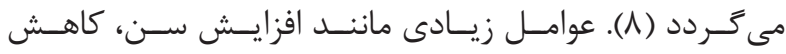

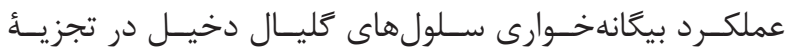

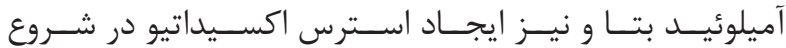

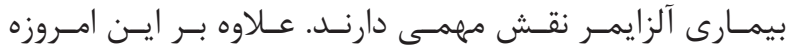

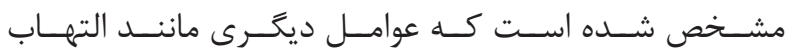

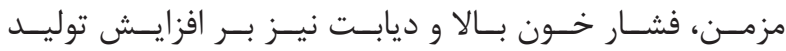

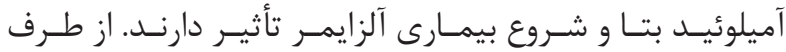

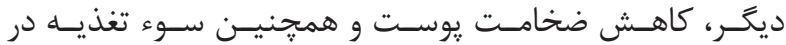

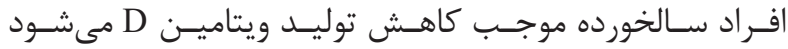

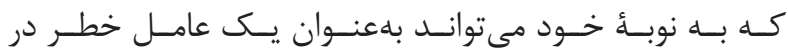

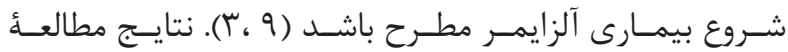

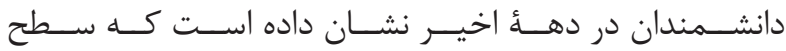

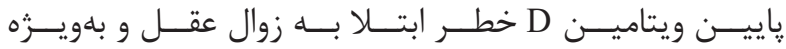

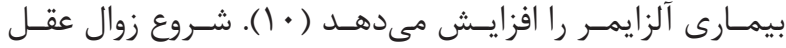

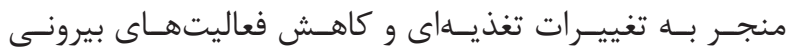

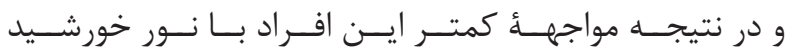

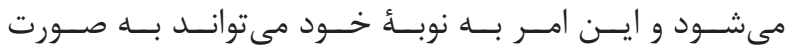

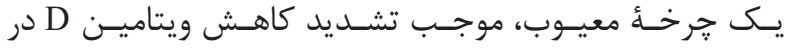

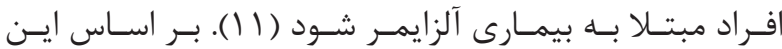

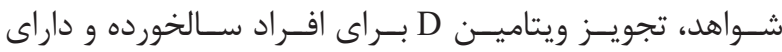

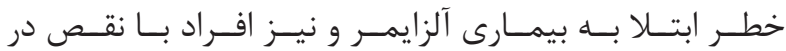

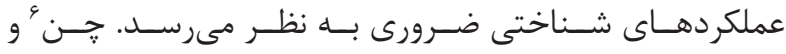

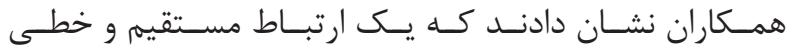

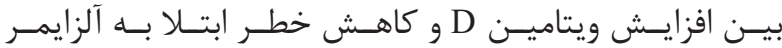

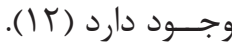

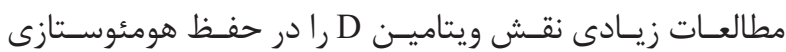

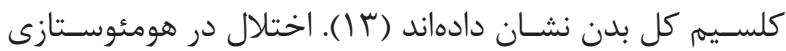

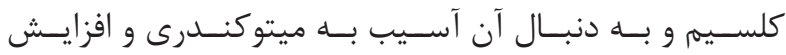

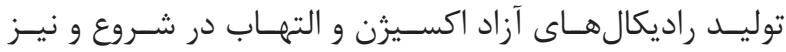

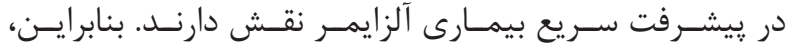

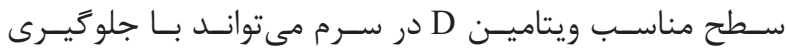

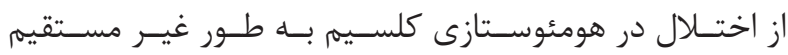

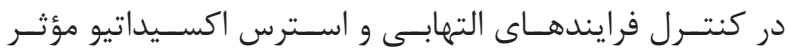

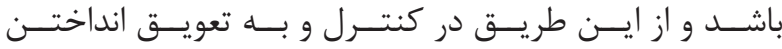

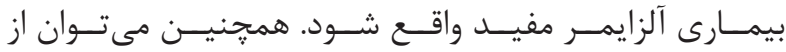

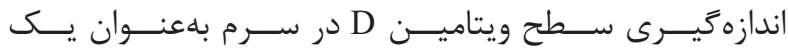

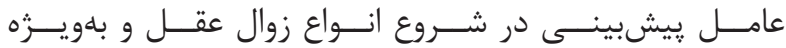

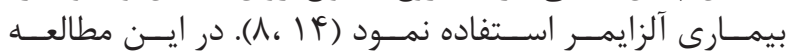

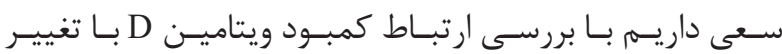

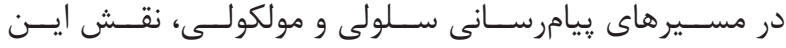

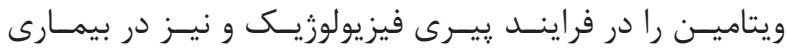

1. 1,25 Dihydroxy cholecalciferol

2. 7- Dehydrocholestrol

${ }^{3 .}$ Neurodegenerativ

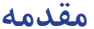

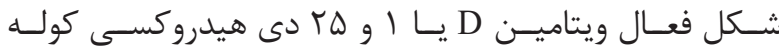

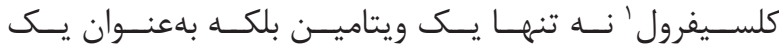

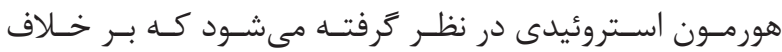

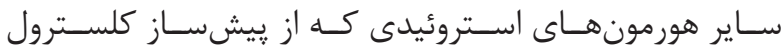

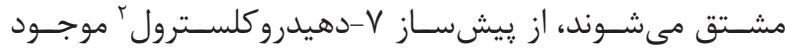

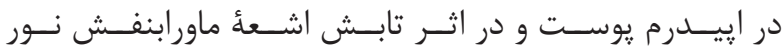

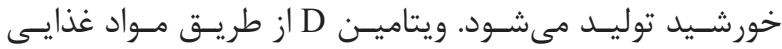

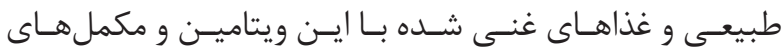

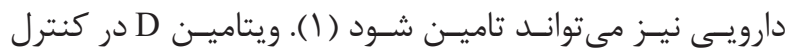

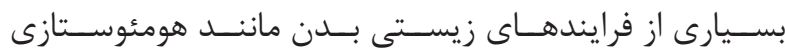

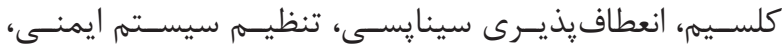

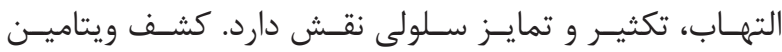

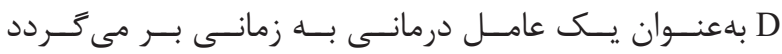

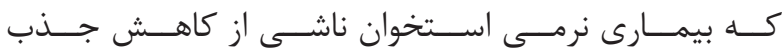

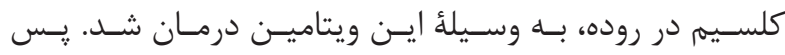

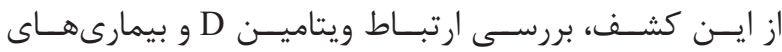

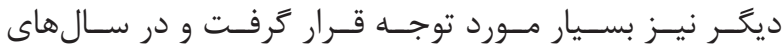

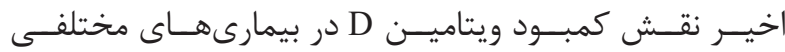

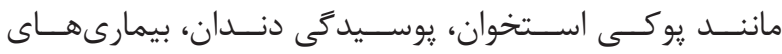

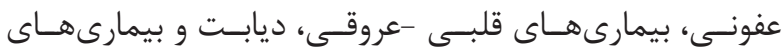

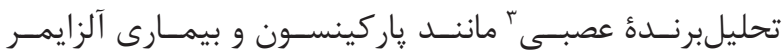

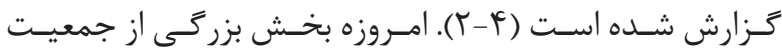

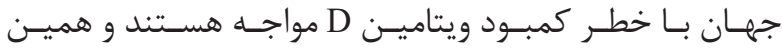

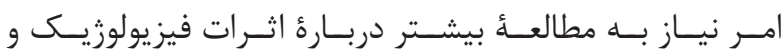

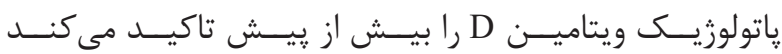

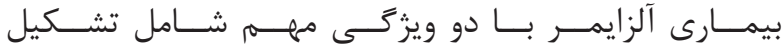

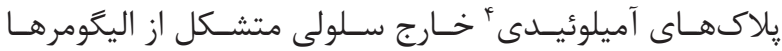

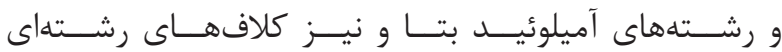

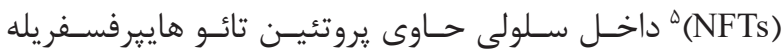

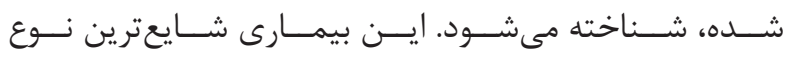

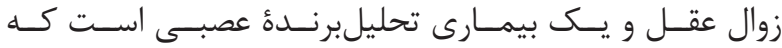

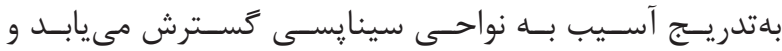

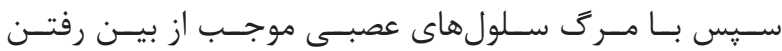

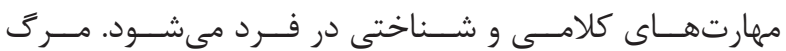

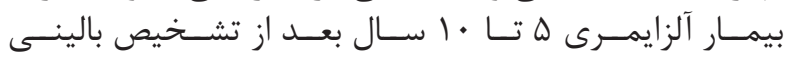

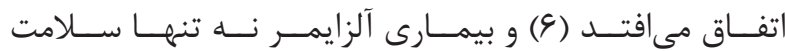

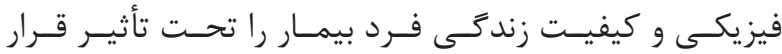

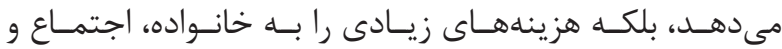

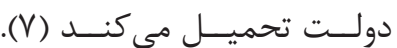

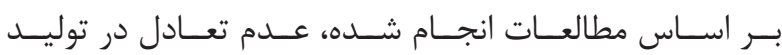

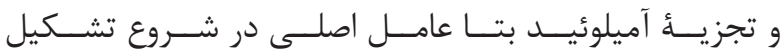

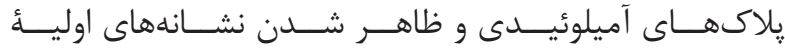

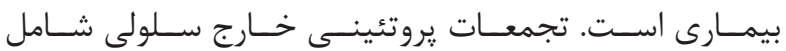

\footnotetext{
4. Amyloid plaques

${ }^{5}$ Neuro fibrillary tangles

${ }^{6}$ Chen
} 


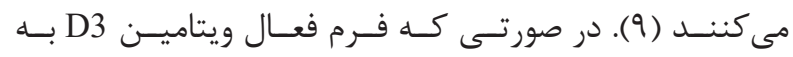

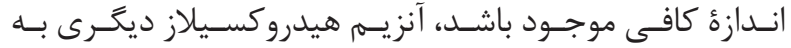

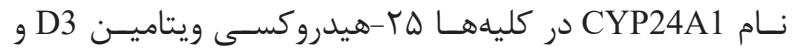

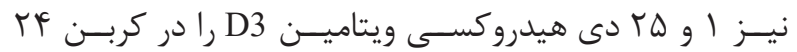

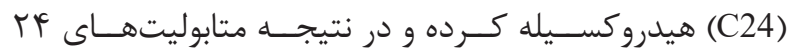

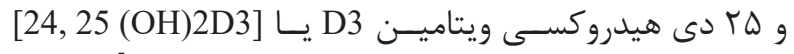

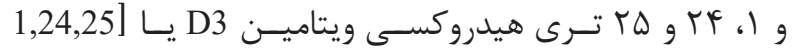

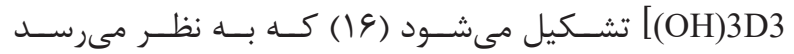

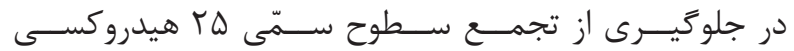

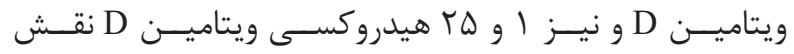

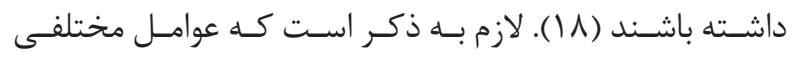

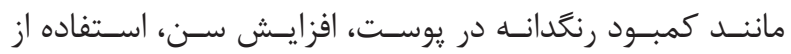

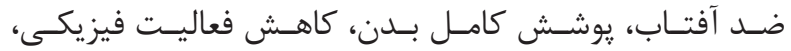

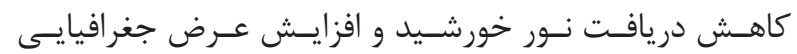

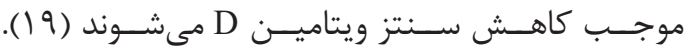
غلظت سر مى ويتامين D D

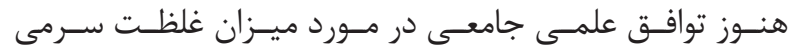

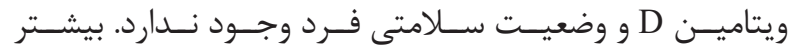

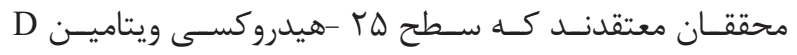

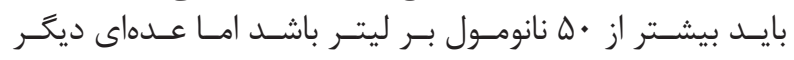

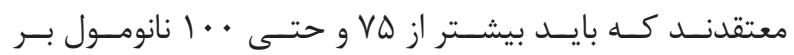

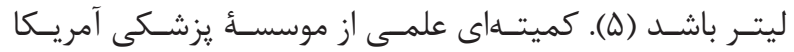

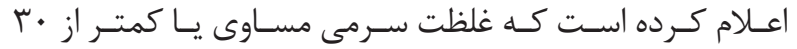

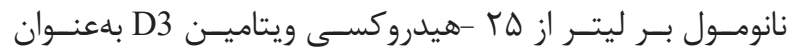

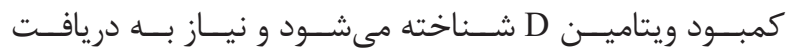

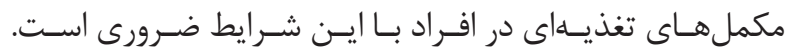

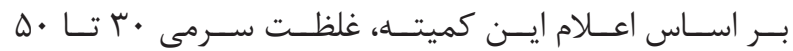

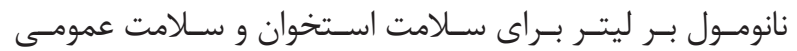

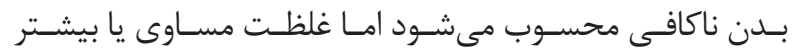

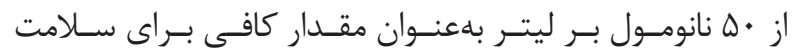

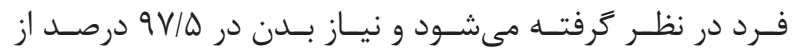

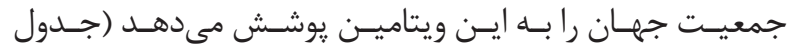

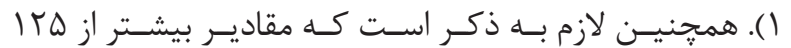

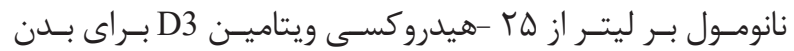

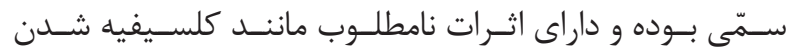

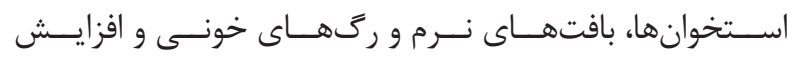

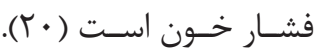

$$
\begin{aligned}
& \text { آلزايمـر بررسـى نماييسهم. } \\
& \text { بيوسنتز ويتامين D }
\end{aligned}
$$

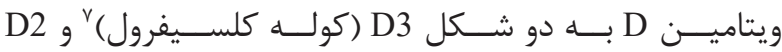

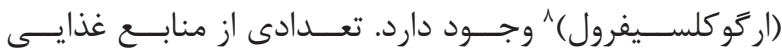

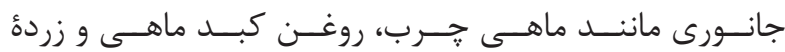

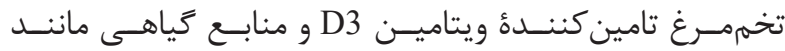

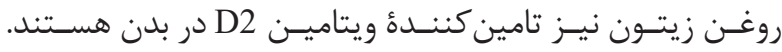

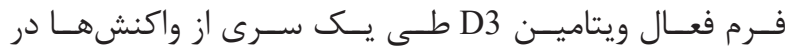

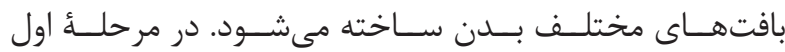

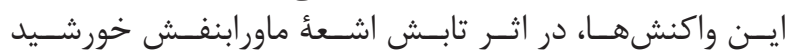

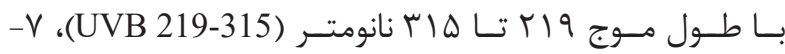

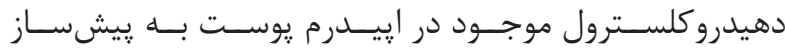

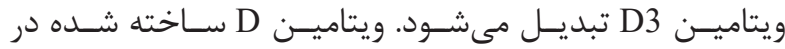

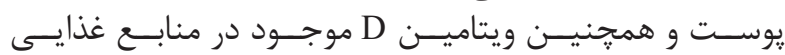

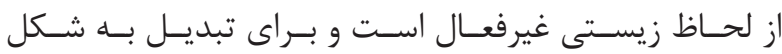

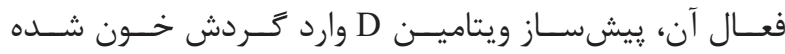

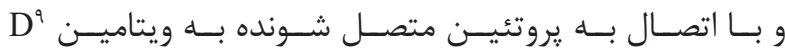

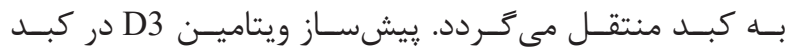

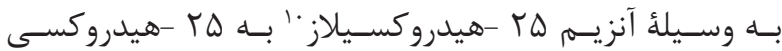

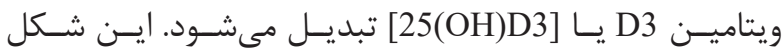

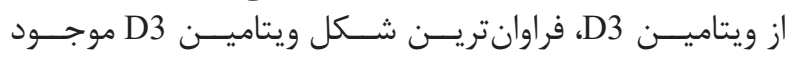

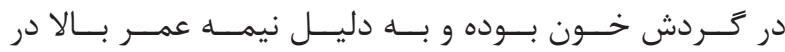

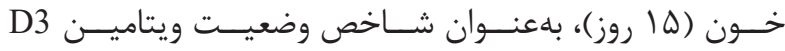

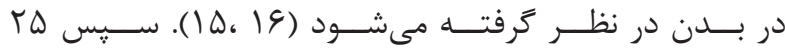

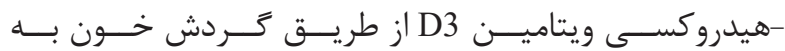

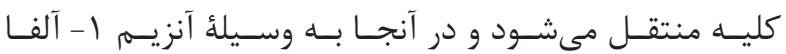

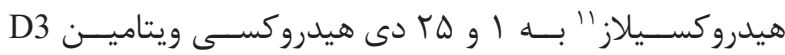

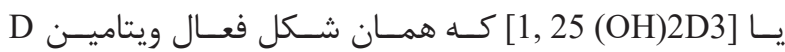

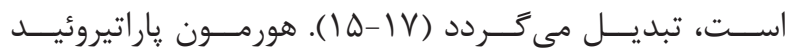
(PTH)

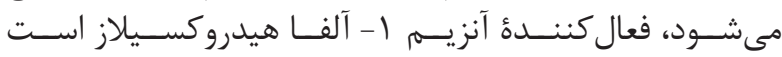

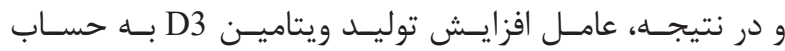

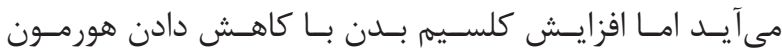

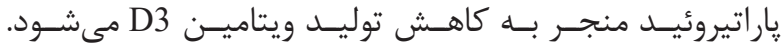

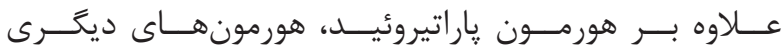

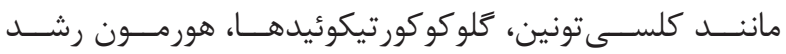

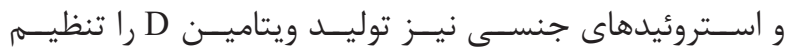

\begin{tabular}{|c|c|c|}
\hline اثرات آن بر وضعيت سلامتى فرد & 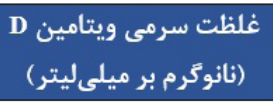 & $\begin{array}{c}\text { D نلظت سرمى ويتامين } \\
\text { D (نانومول بر ليتر) }\end{array}$ \\
\hline كمبود ويتامين D موجب نرمى استخوان در كودكان و يوكى درى استخان & كمتر از كا & كمتر از ·r \\
\hline مقدار ناكافى براى سلامت استخوان و سلامت عمومى فرد سالم & r & $\Delta \cdot r$. \\
\hline مقدار كافى براى سلامت استخوان و سلامت عمومى فرد سالم & r مساوى و بيشتر از ·r & مساوى و بيشتر از •هـ \\
\hline ل داراى اثرات نامطلوب & بيشتر از •د & بيشتر از \\
\hline
\end{tabular}

جدول ا- غلظت سرمى فا- هيدروكسى ويتامين D و اثر آن بر وضعيت سلامتى فرد (• (T).

7. Cholecalciferol

8. Ergocalciferol

9. Vitamin D binding protein
10.25-Hydroxylase or cytochrome P450 2R1 (CYP2R1)

11. Cytochrome P450 27B1 (CYP27B1)

12. Parathyroid hormone 


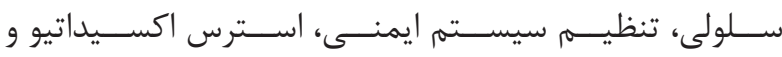

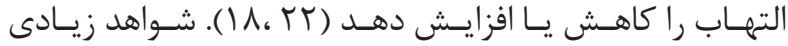

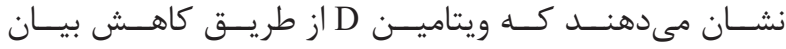

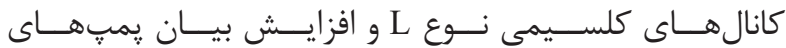

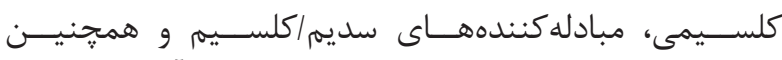

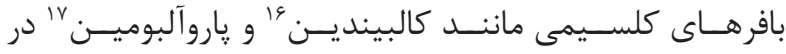

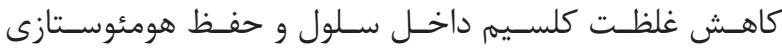

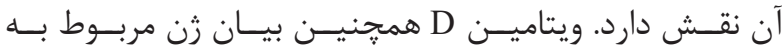

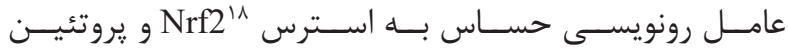

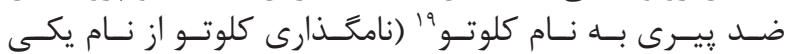

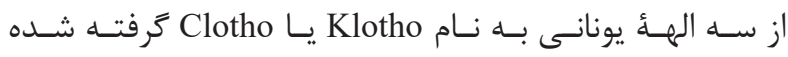

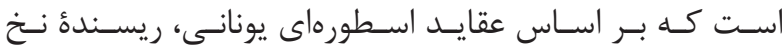

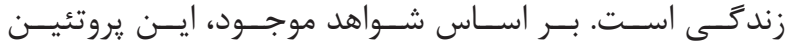

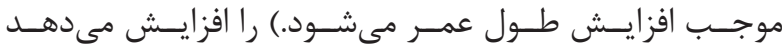

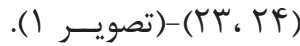

از مدتهــا يــش مشـخص شـده اسـت كـه عـلاوه بــر اثـرات
اثرات زنوميك و غير زنوميك ويتامين D

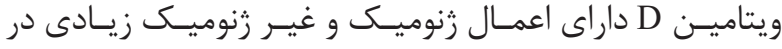

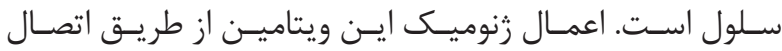

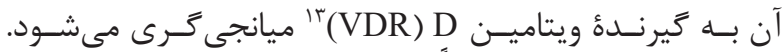

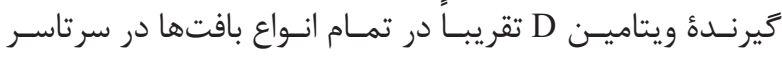

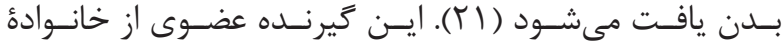

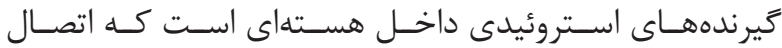

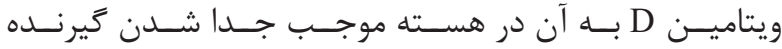

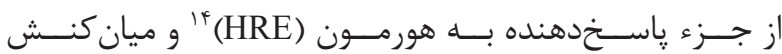

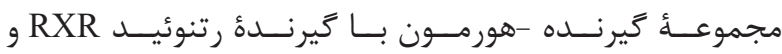

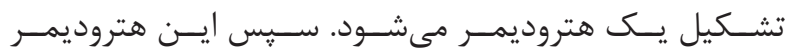

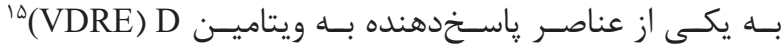

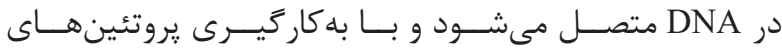

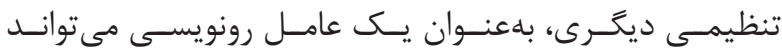

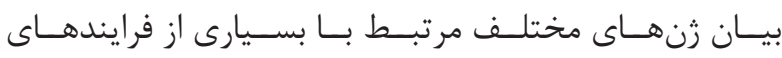

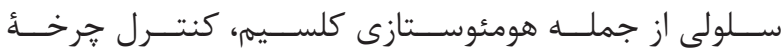

\section{در شر ايط ميزان طبيعى ويتامين}

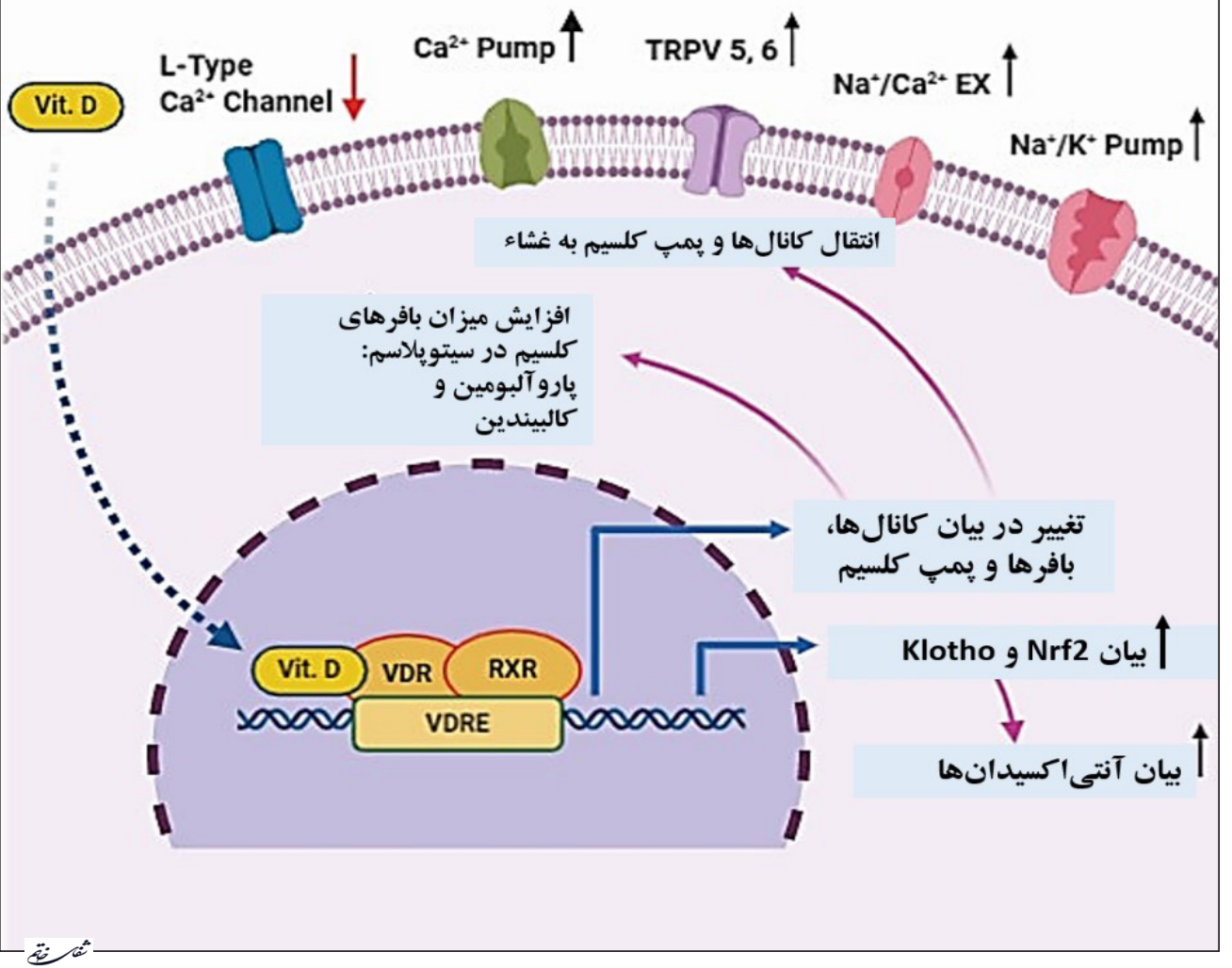

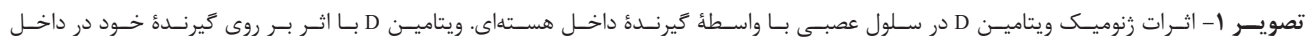

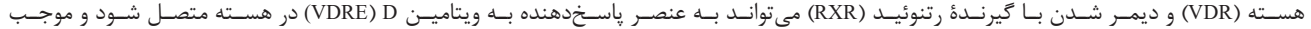

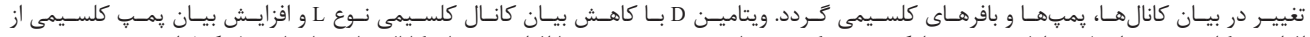

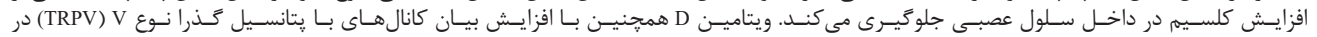

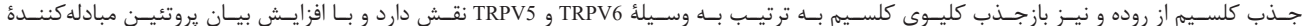

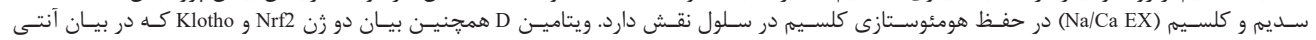

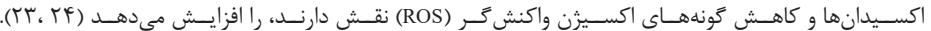

13. Vitamin D receptor
14. Hormone response element
15. Vitamin D response element

15. Vitamin D
${ }^{16}$ Calbindin
${ }^{17}$ Parvalbumin

${ }^{18}$ Nuclear factor erythroid-2 related factor 2

${ }^{19}$ Klotho 


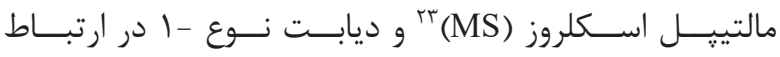

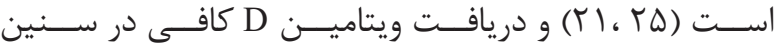

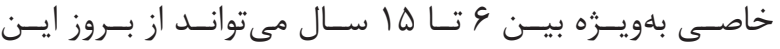

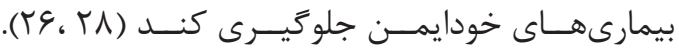

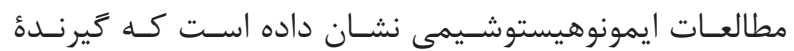

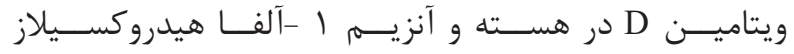

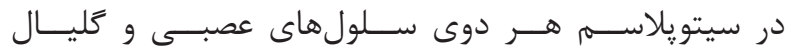

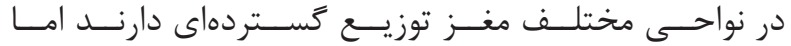

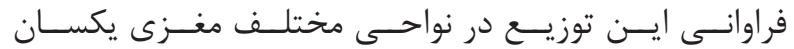

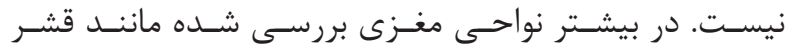

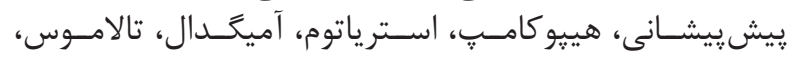

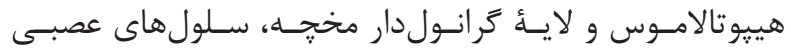

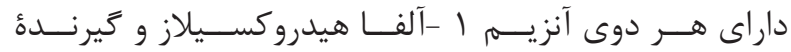

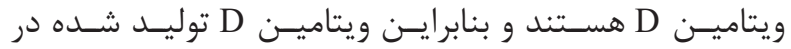

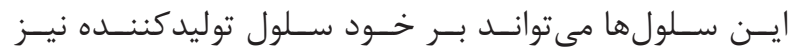

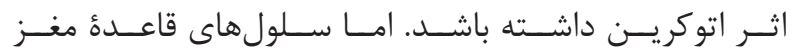

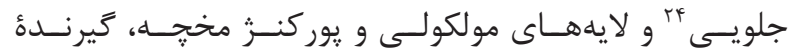

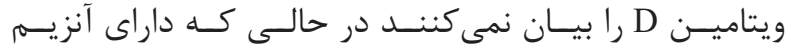

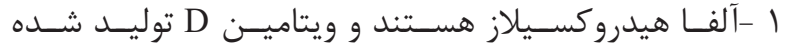

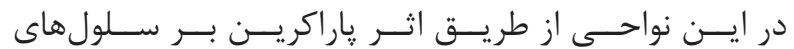

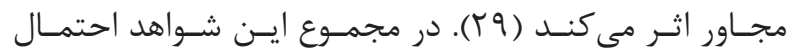

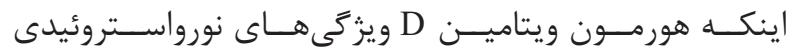

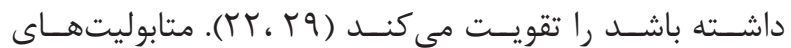

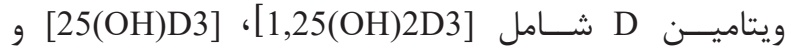

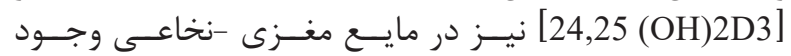

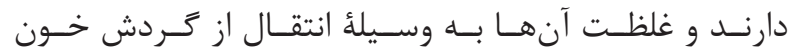

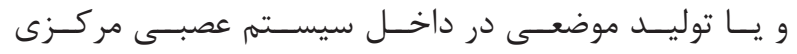

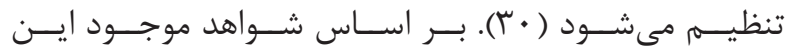

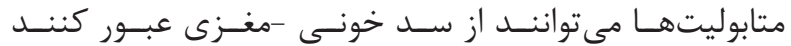

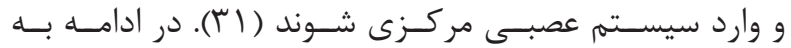

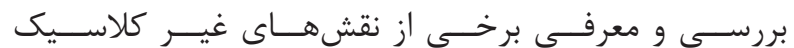

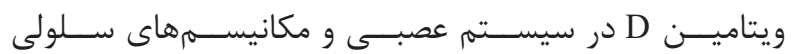

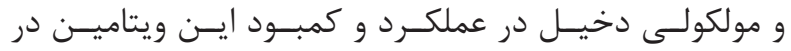

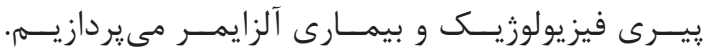

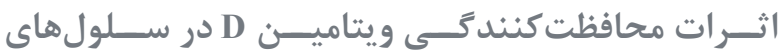
عصبى ويتاميـن D در سـلولهاى عصبـى نقــ محافظتـى دارد كــهـ

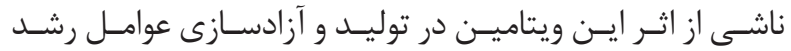

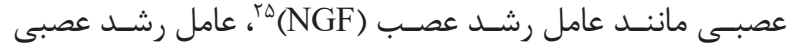

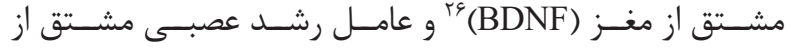

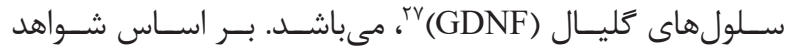

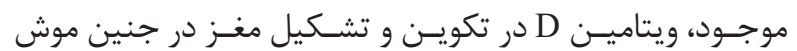

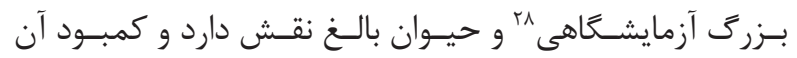

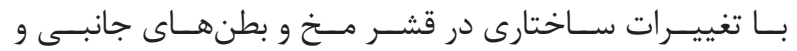

\footnotetext{
${ }^{20}$ Inositol-3-phosphate

${ }^{21}$ Mitogen-activated protein (MAP) kinases

${ }^{22}$ Mineralization

${ }^{23}$ Multiple sclerosis

${ }^{24}$ Basal forebrain
}

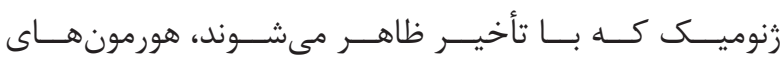

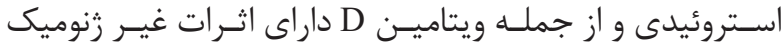

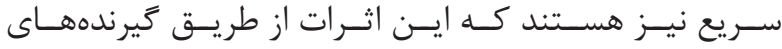

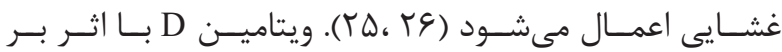

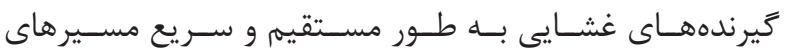

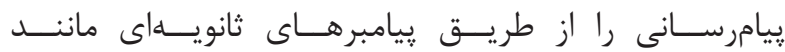

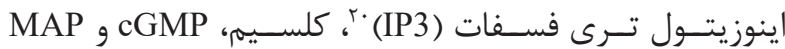

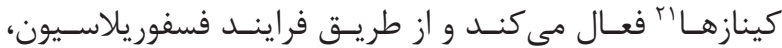

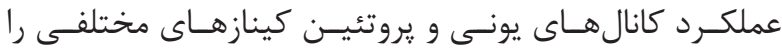

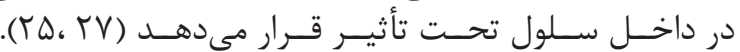

اعمال كلاسيك و غير كلاسيك ويتامين Dين

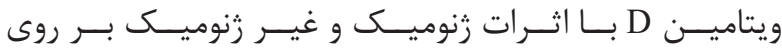

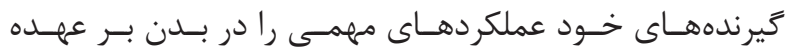

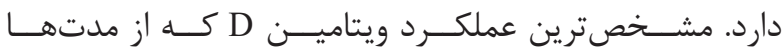

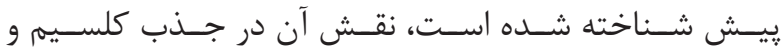

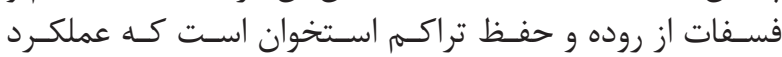

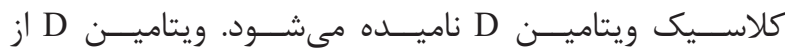

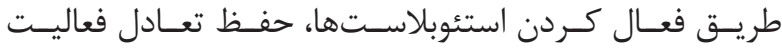

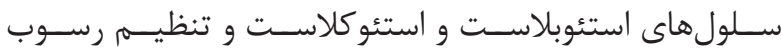

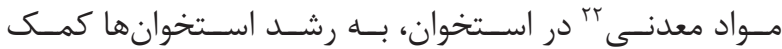

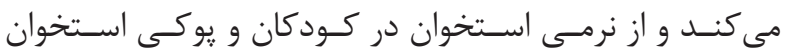

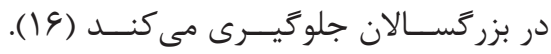

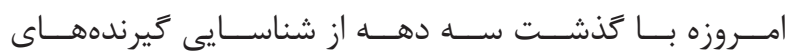

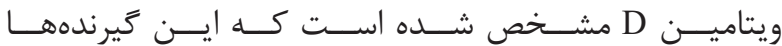

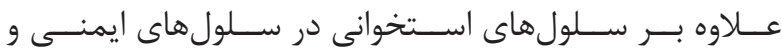

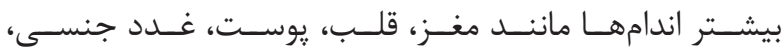

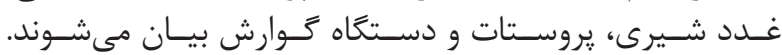

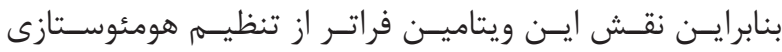

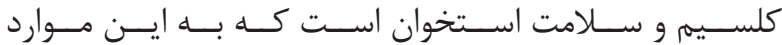

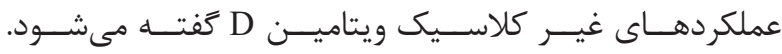

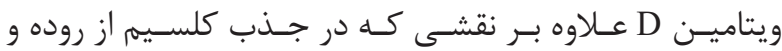

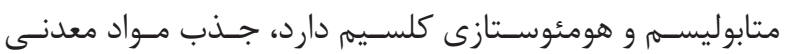

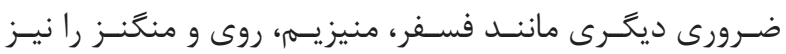

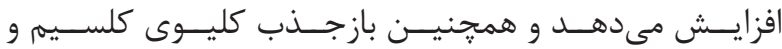

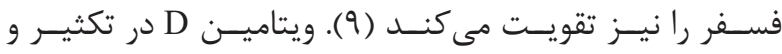

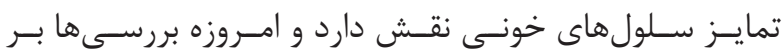

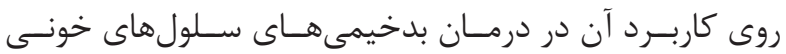

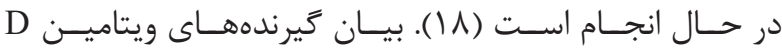

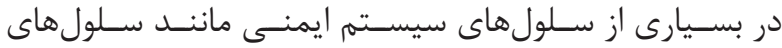

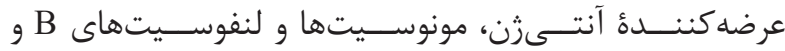

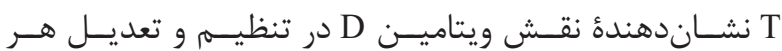

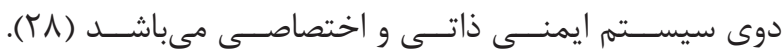

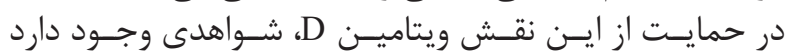

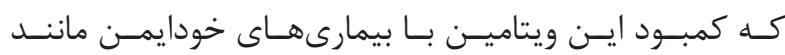

\footnotetext{
${ }^{25}$ Nerve growth factor

${ }^{26}$ Brain- derived neurotrophic factor

${ }^{27}$ Glia- derived neurotrophic factor

${ }^{28}$ Rat
} 


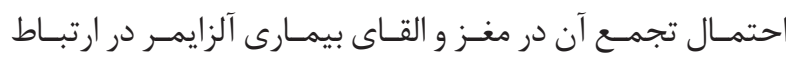

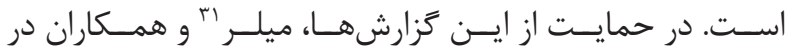

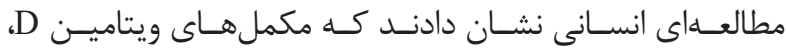

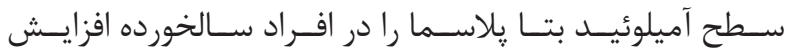

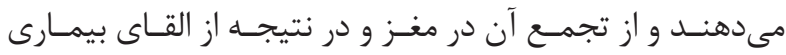

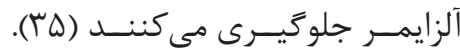

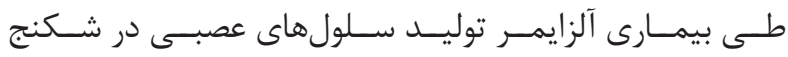

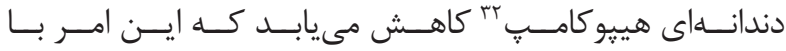

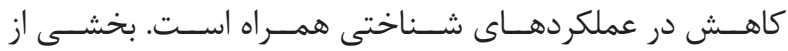

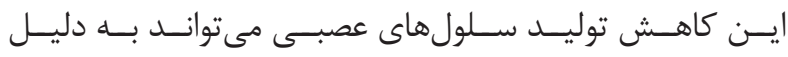

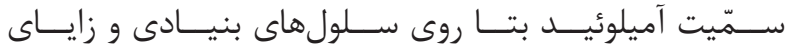

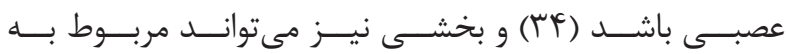

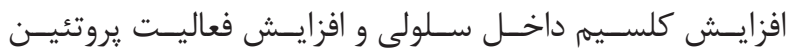

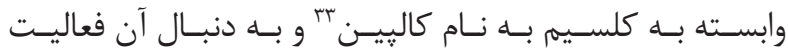

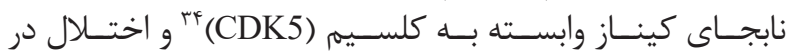

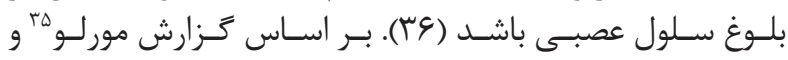

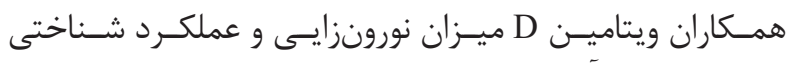

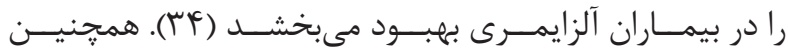

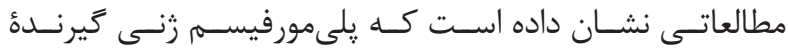

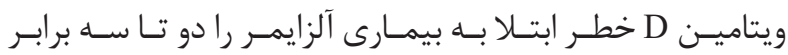

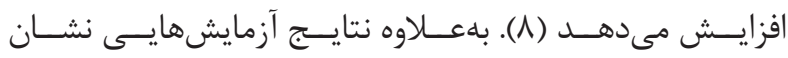

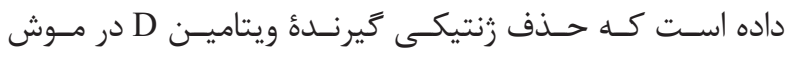

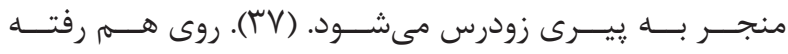

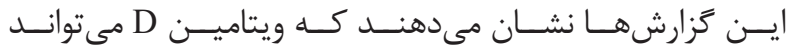

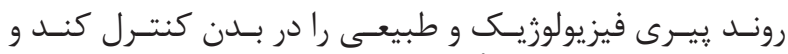

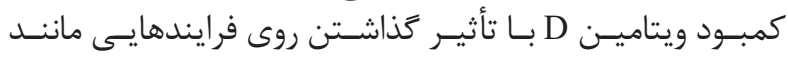

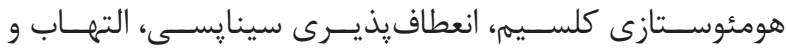

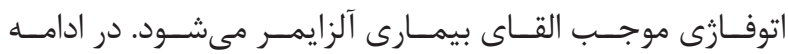

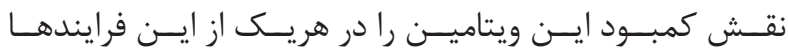
بر رسـى مىنماييسمه.

كمبود ويتامين D و اختلال در هومئوستازى كلسيم

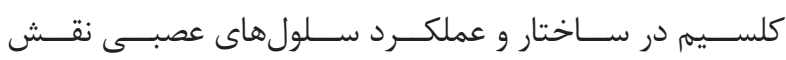

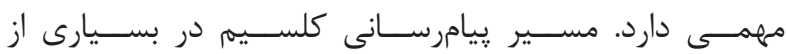

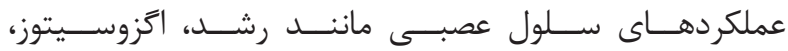

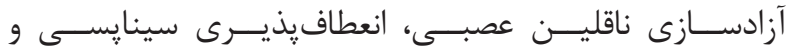

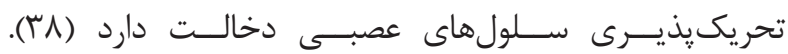

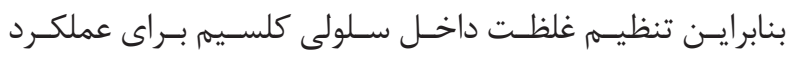

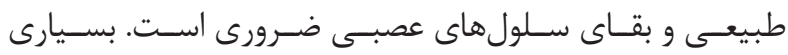

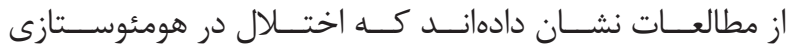

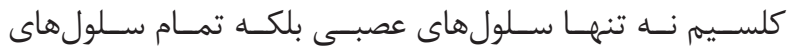

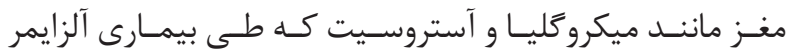

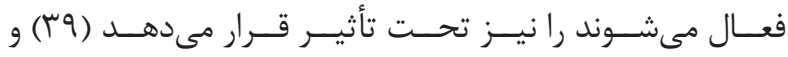

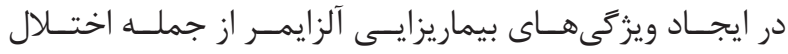

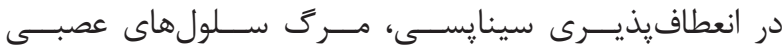

${ }^{29}$ Choline acetyl transferase

${ }^{30}$ Neurotransmitter

${ }^{31}$ Miller

${ }^{32}$ Hippocampal dentate gyrus

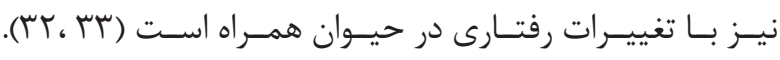

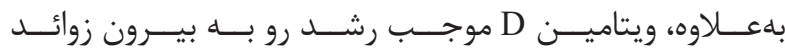

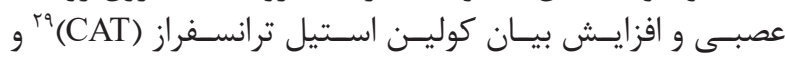

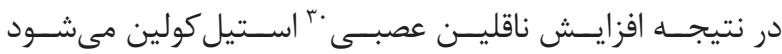

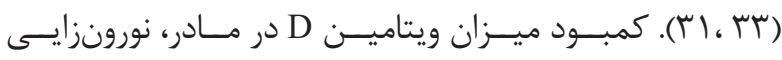

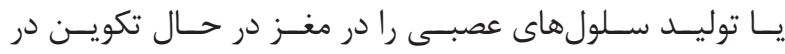

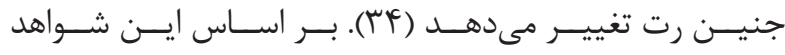

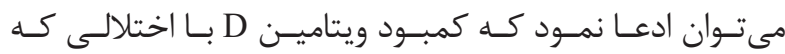

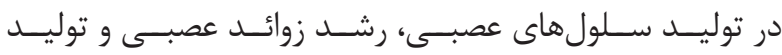

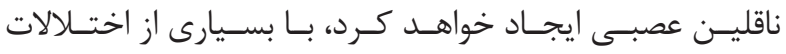

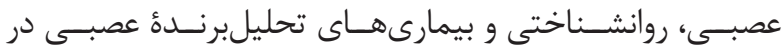

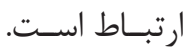
نقش ويتامين D در فرايند يبيرى و بيمارى آلزايمر

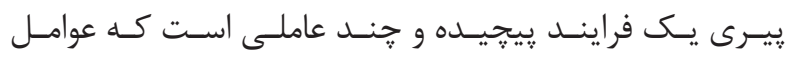

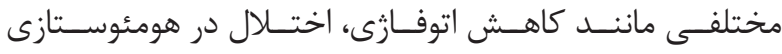

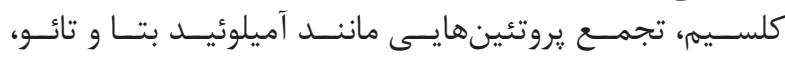

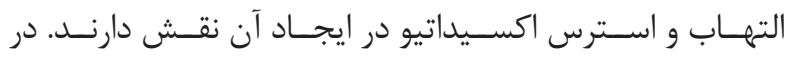

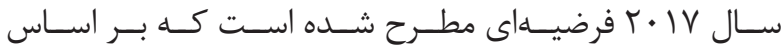

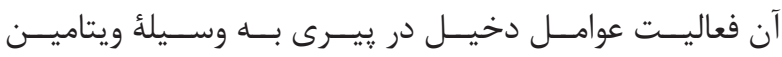

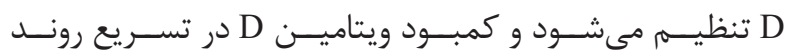

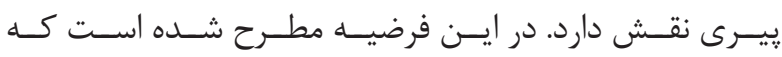

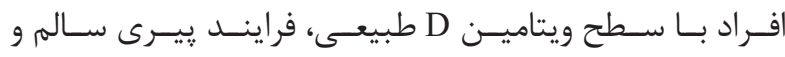

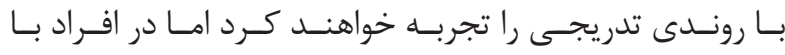

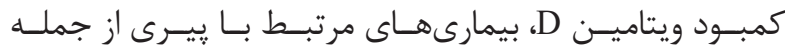

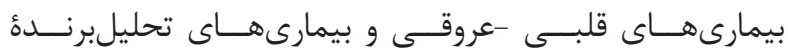

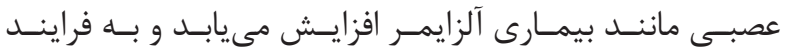

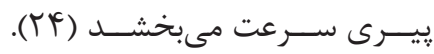

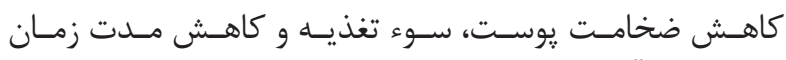

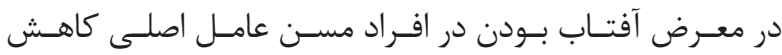

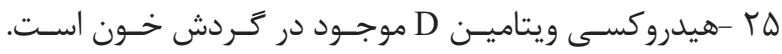

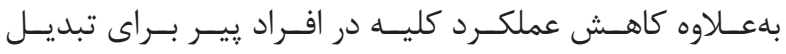

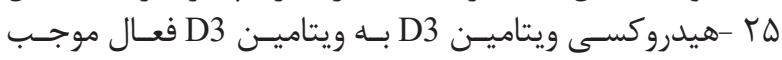

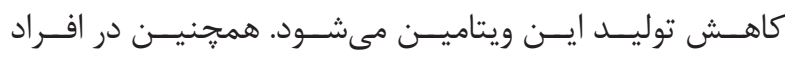

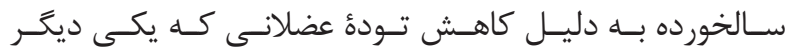

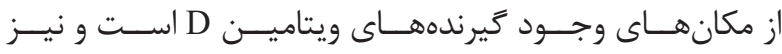

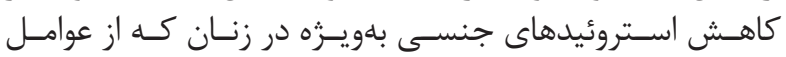

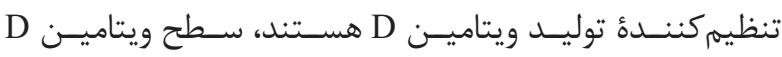

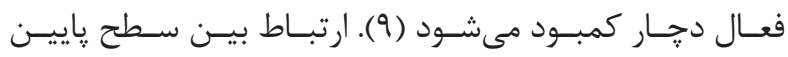

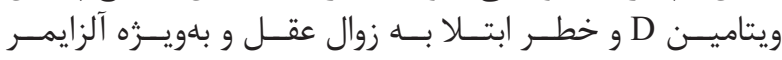

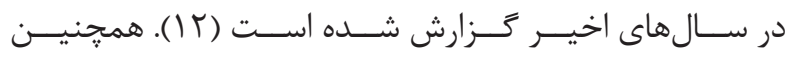

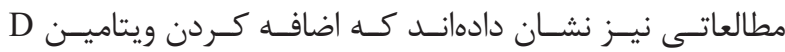

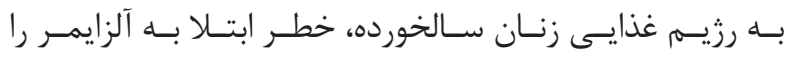

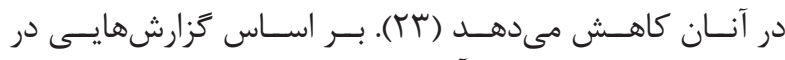

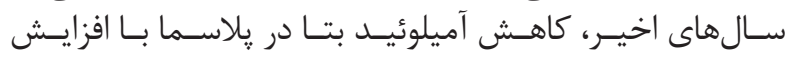

\footnotetext{
${ }^{33}$ Calpain

${ }^{34}$ Calcium-dependent kinase 5

${ }^{35}$ Morello
} 


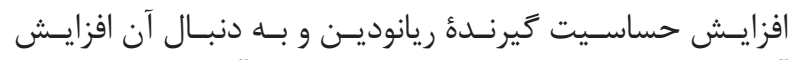

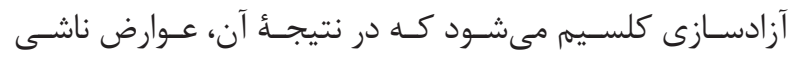

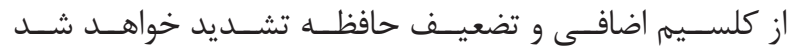

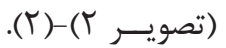

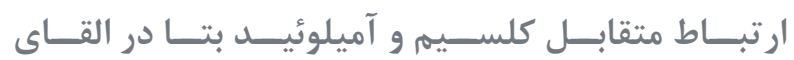

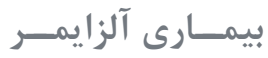

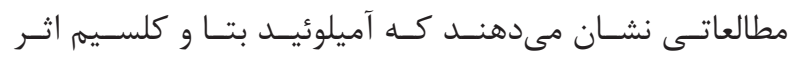

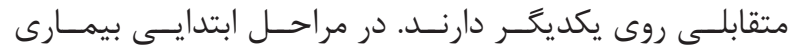

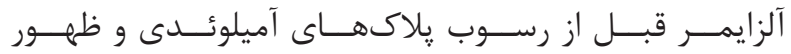

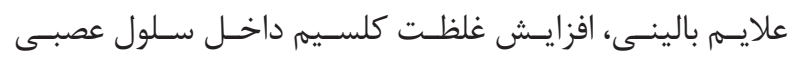

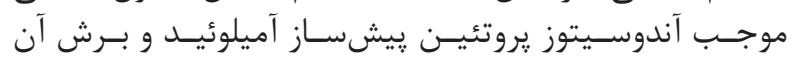

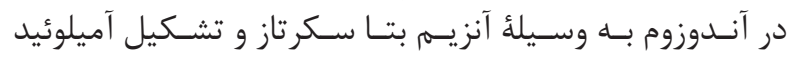

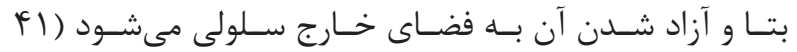

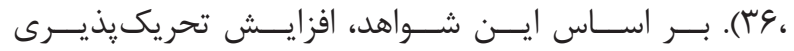

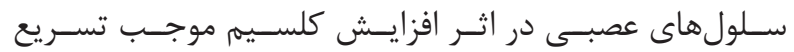

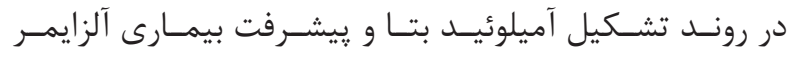

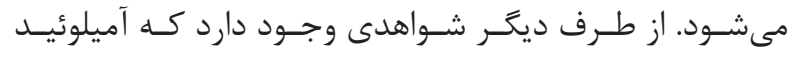

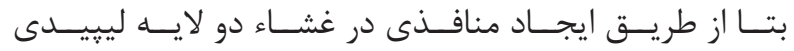

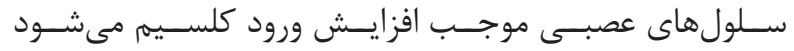

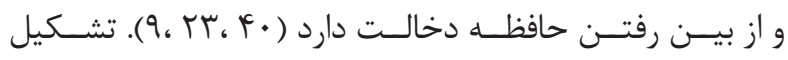

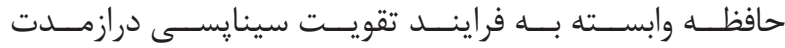
(LTP)

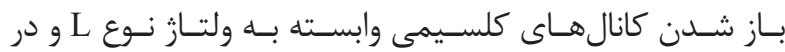

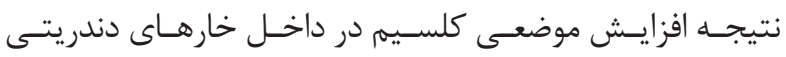

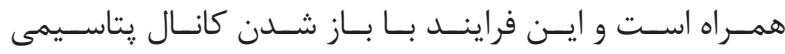

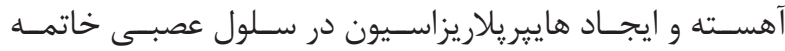

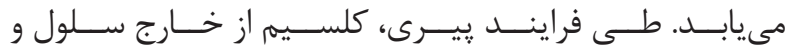

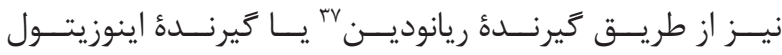

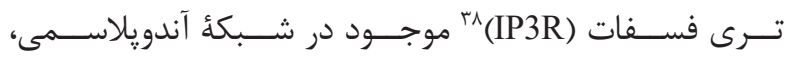

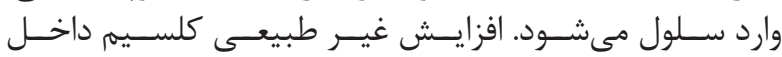

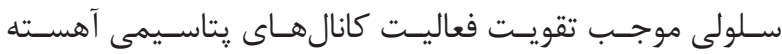

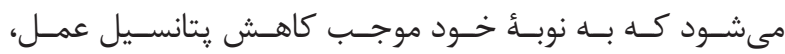

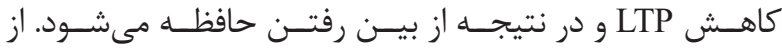

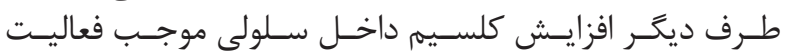

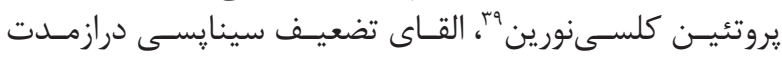

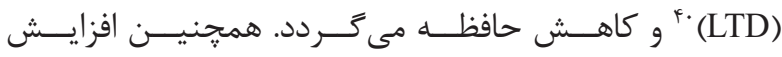

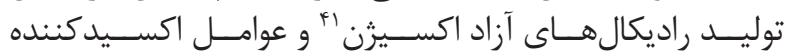

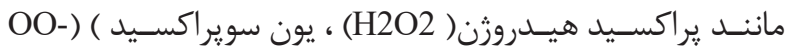

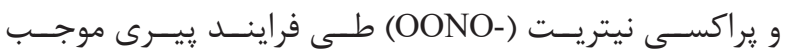

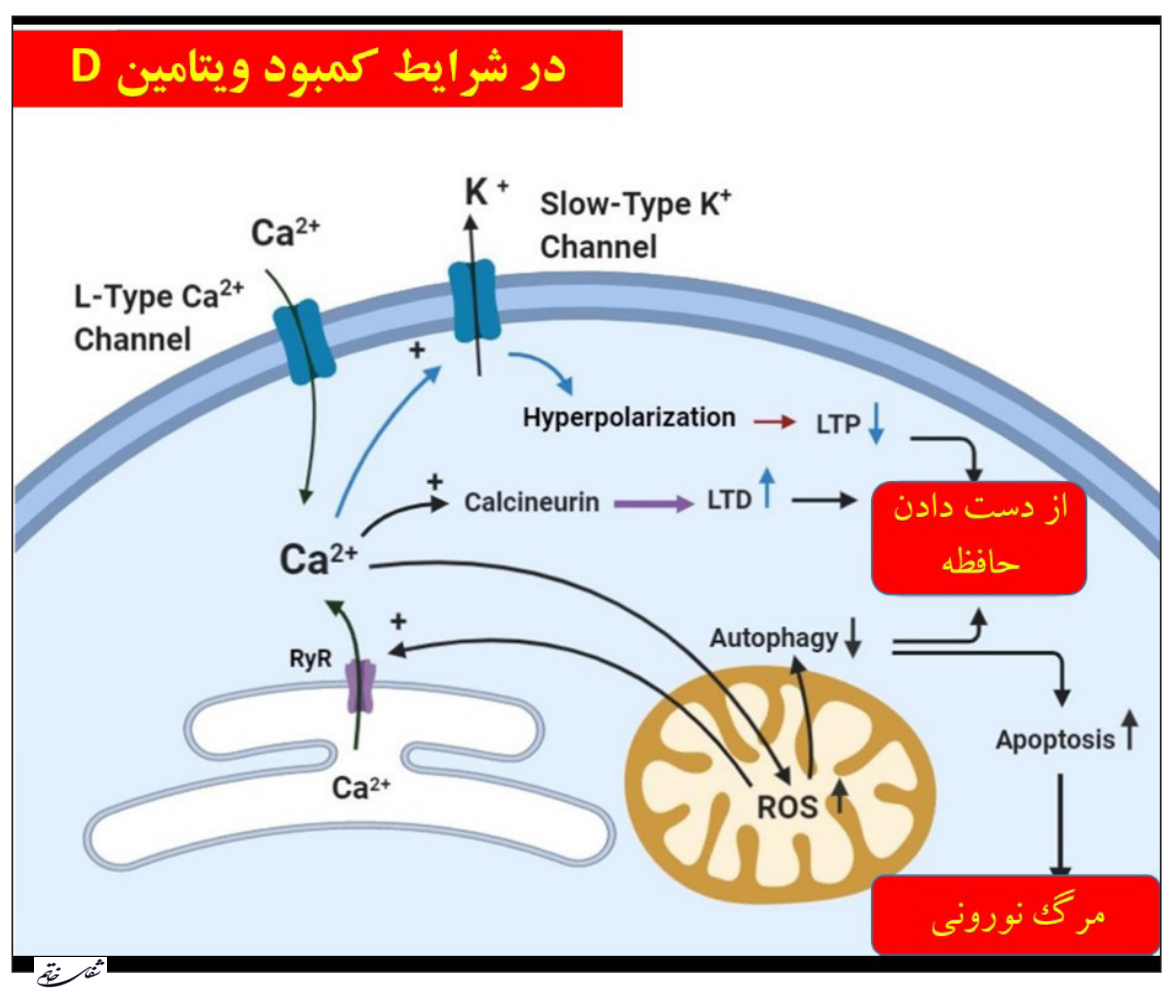

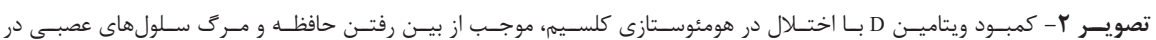

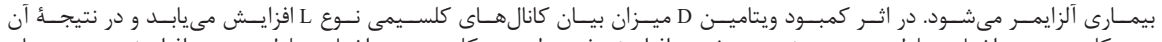

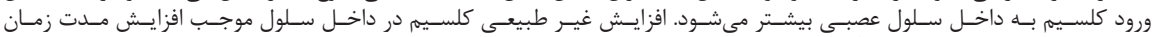

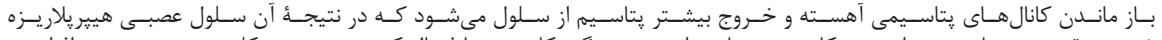

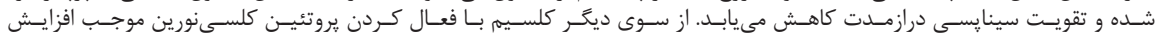

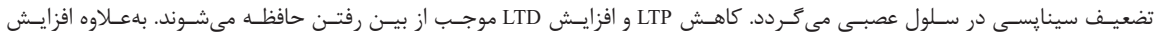

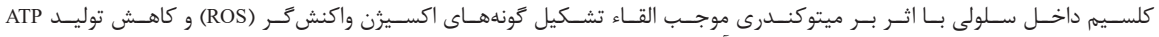

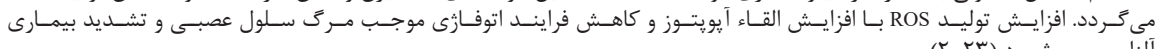

${ }^{36}$ Long- term potentiation

${ }^{37}$ Ryanodine receptor

${ }^{38}$ Inositol-3-phosphate receptor

\section{${ }^{39}$ Calcineurin}

${ }^{40}$ Long- term depression

${ }^{41}$ Reactive oxygen specious 


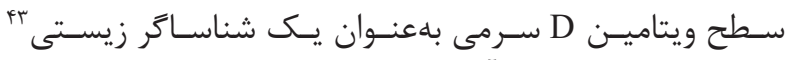

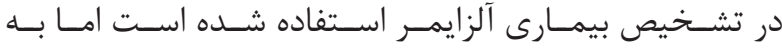

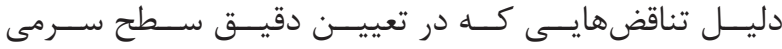

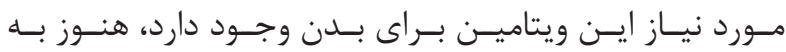

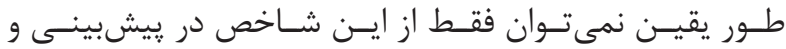

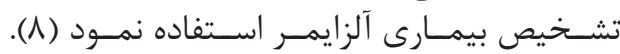

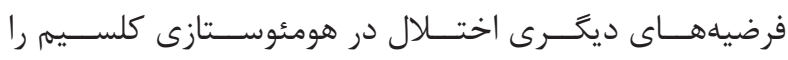

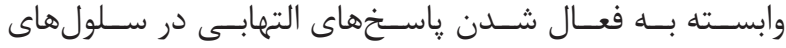

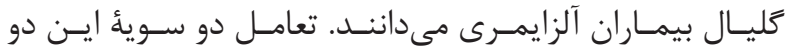

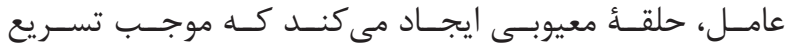

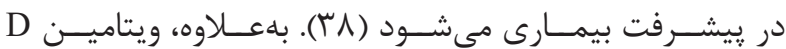

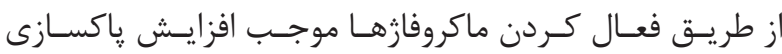

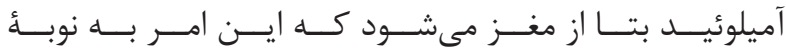

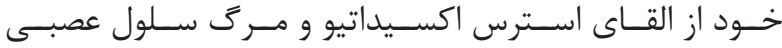

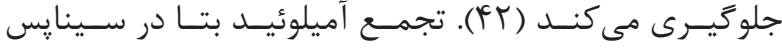

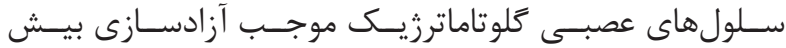

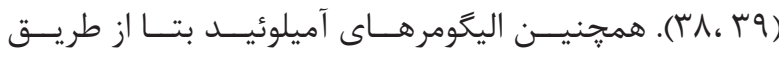

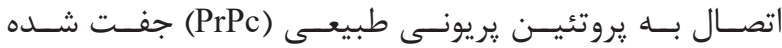

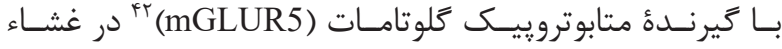

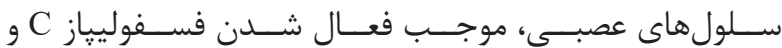

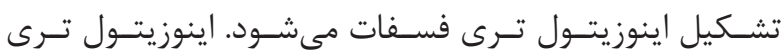

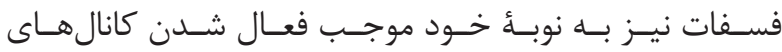

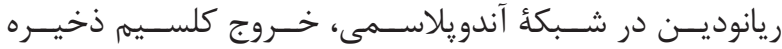

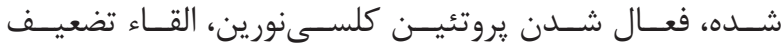

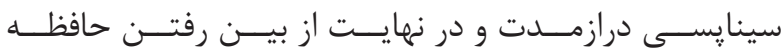

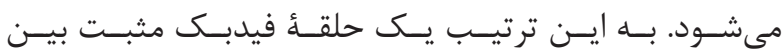

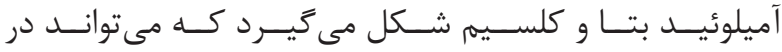

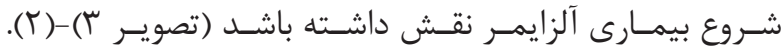

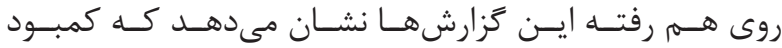

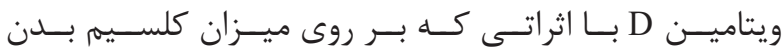

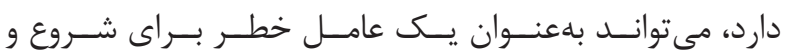

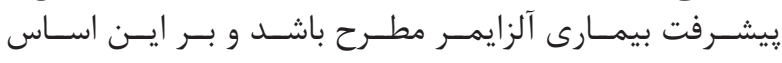

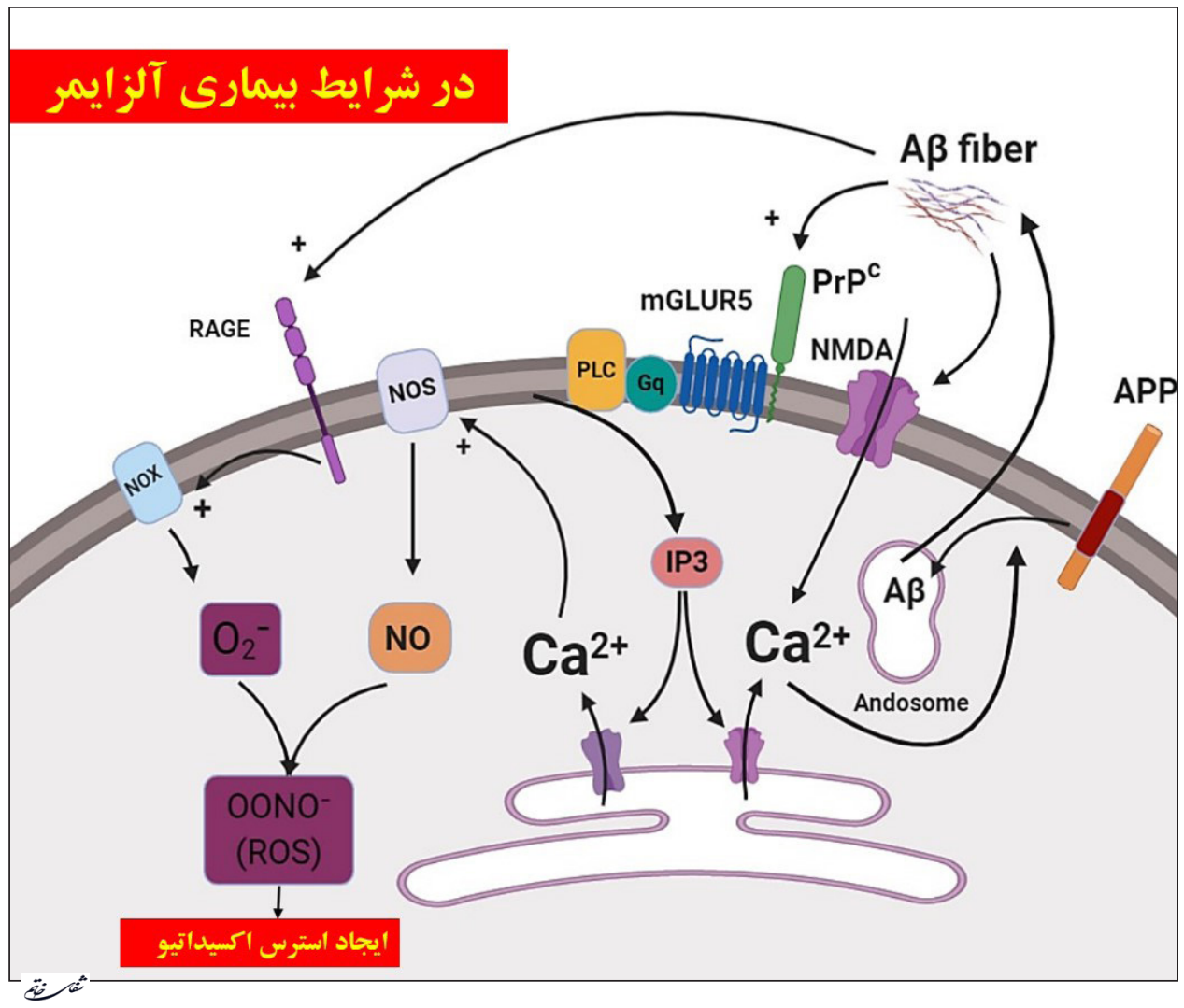

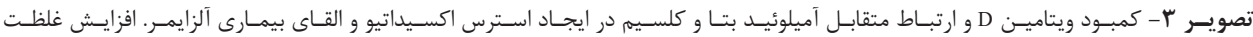

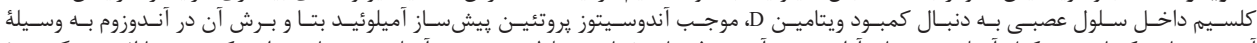

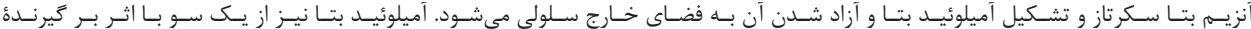

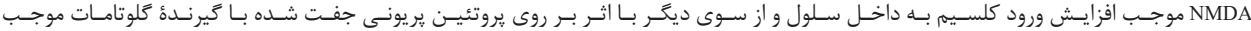

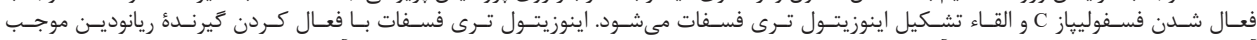

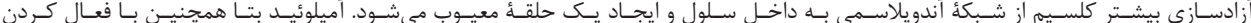

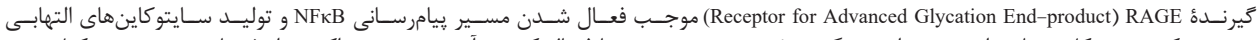

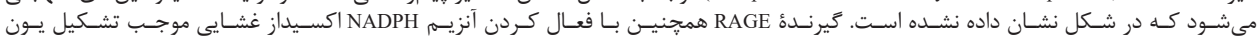

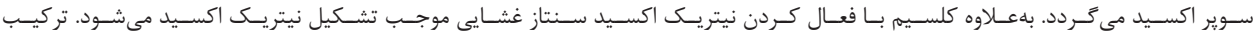

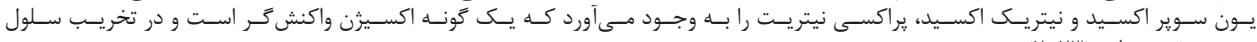

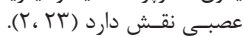

${ }^{42}$ Metabotropic glutamate receptor 5

${ }^{43}$ Biomarker 


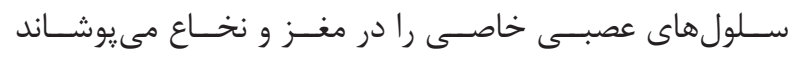

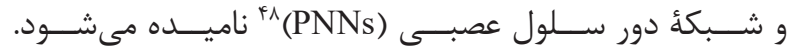

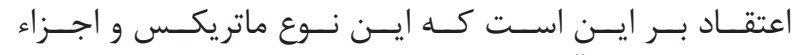

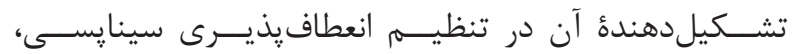

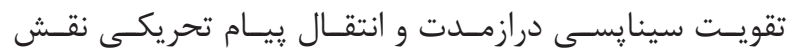

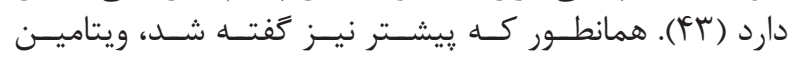

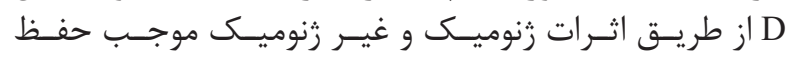

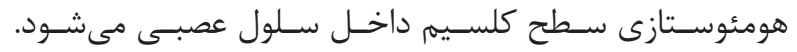

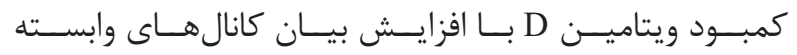

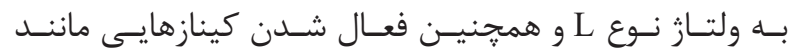

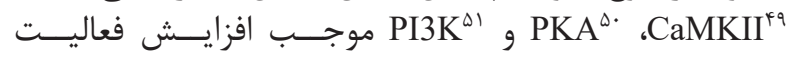

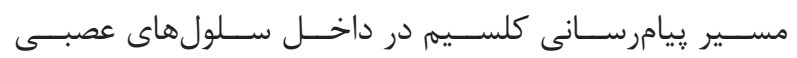

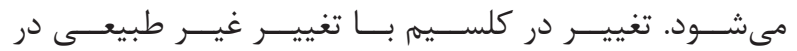

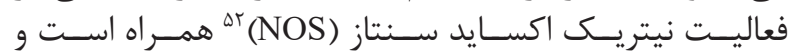

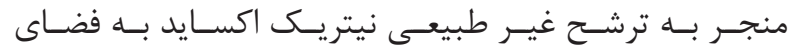

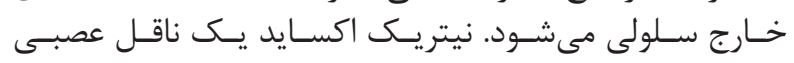

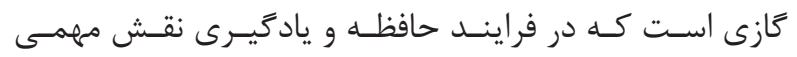

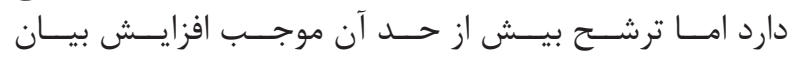

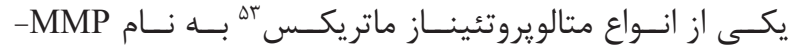

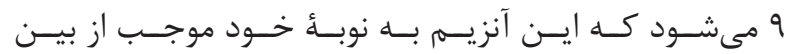

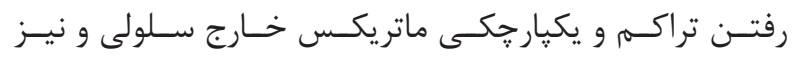

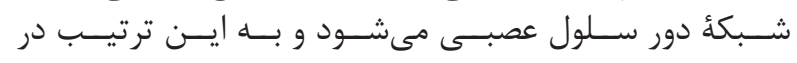

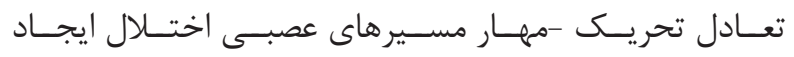

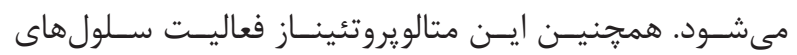

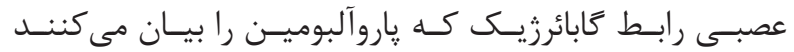

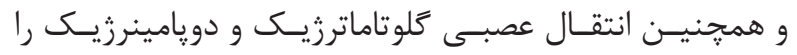

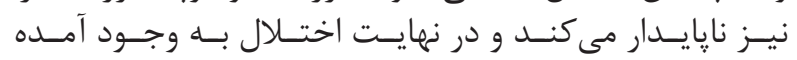

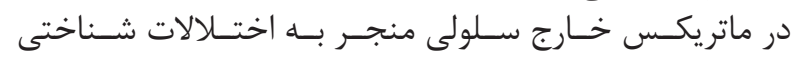

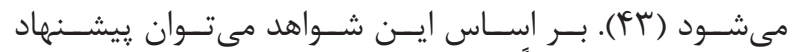

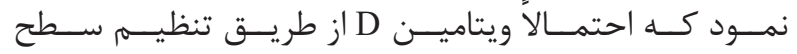

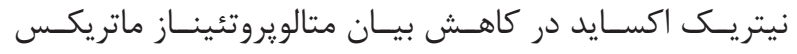

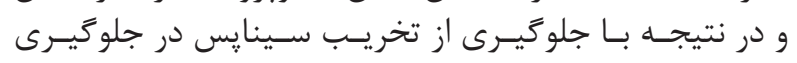

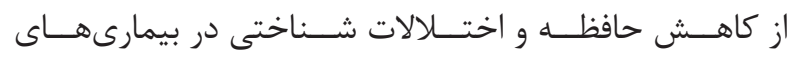

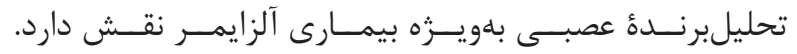

\section{كمبود ويتامين D و نقش آن در فرايند التهاب}

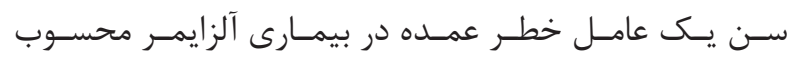

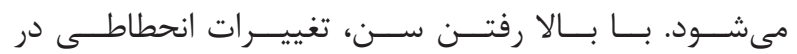

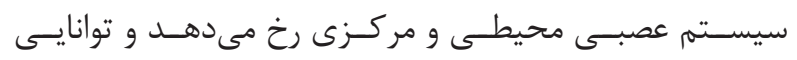

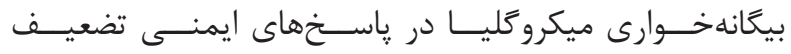

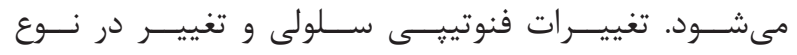

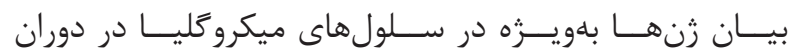

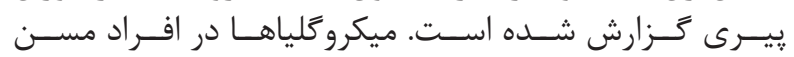

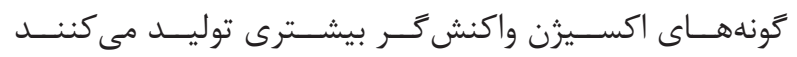

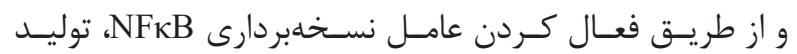

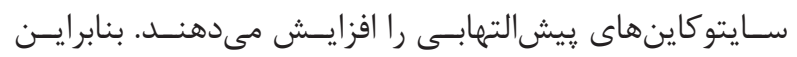

\footnotetext{
${ }^{44} \mathrm{~N}$-methyl-D-aspartate receptors

${ }^{45}$ Annweiler

${ }^{46}$ Synaptic plasticity

${ }^{47}$ Extra cellular matrix

${ }^{48}$ Peri neuronal networks
}

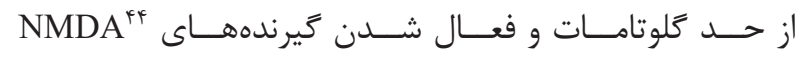

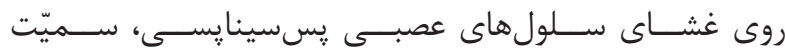

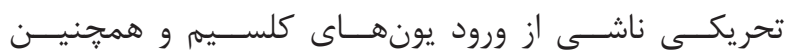

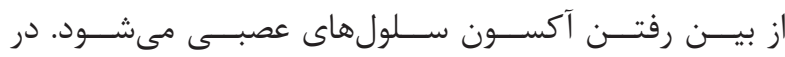

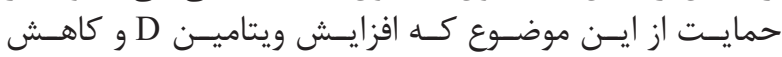

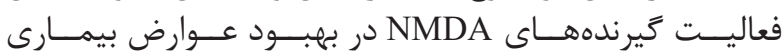

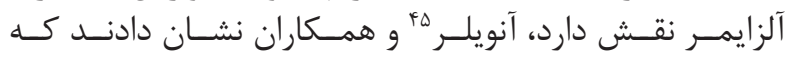

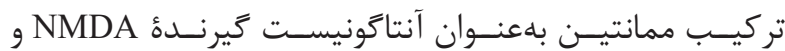

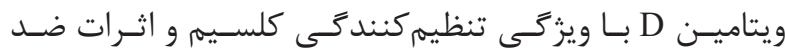

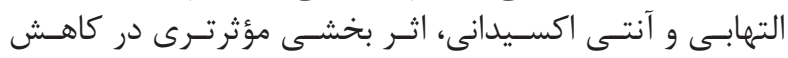

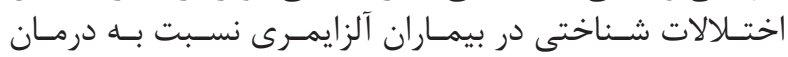

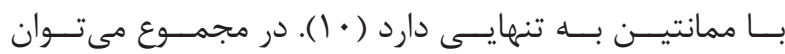

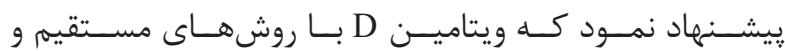

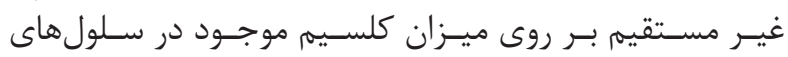

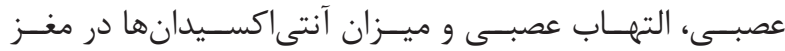

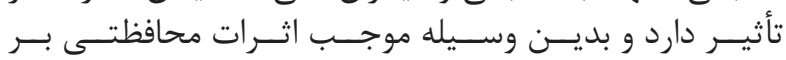

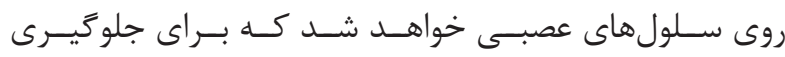

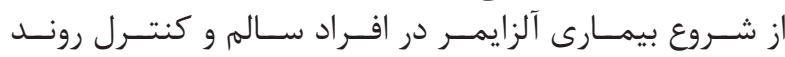

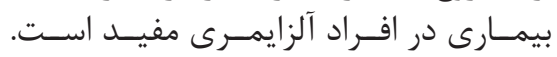

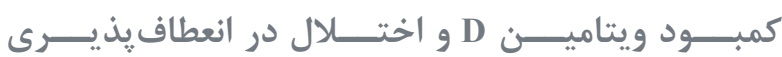
سينا يســــ

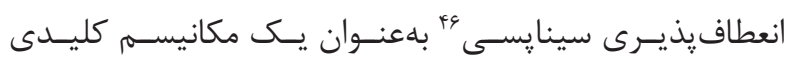

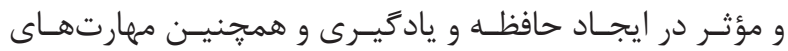

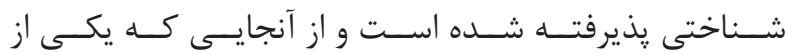

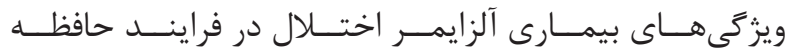

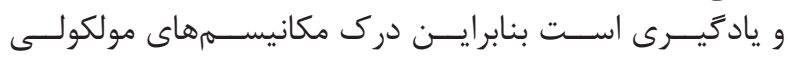

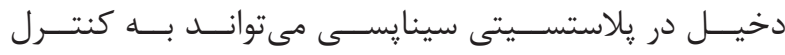

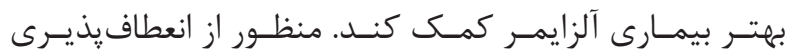

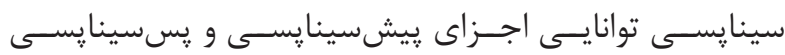

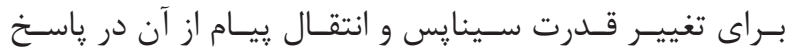

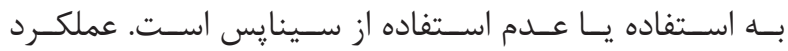

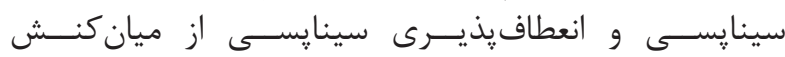

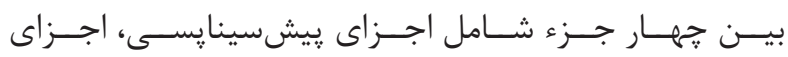

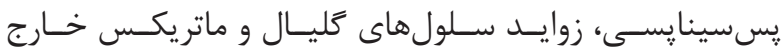

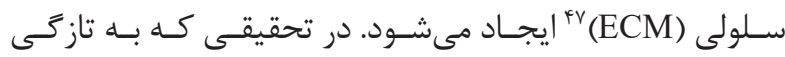

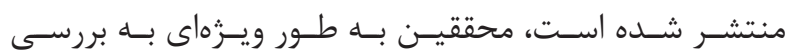

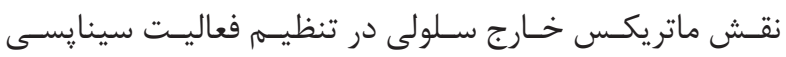

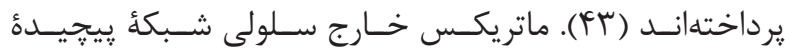

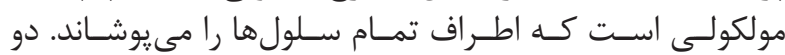

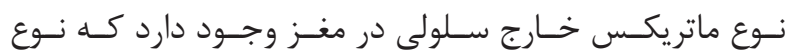

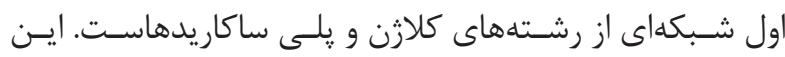

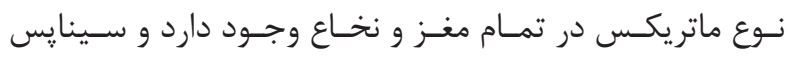

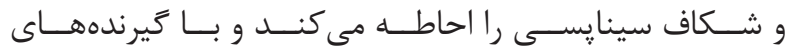

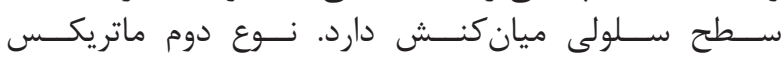

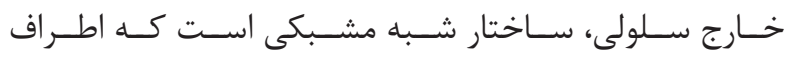

${ }^{49} \mathrm{Calcium} /$ calmodulin-dependent protein kinase II

${ }^{50}$ Protein kinase A

${ }^{51}$ Phosphoinositide 3-kinase

${ }^{52}$ Nitric oxide synthase

${ }^{53}$ Matrix metalloproteinase 9 
نشـان داده اسـت كـهـ اختـلال در زن klotho با بيــرى زودرس،

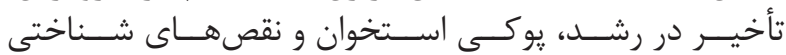

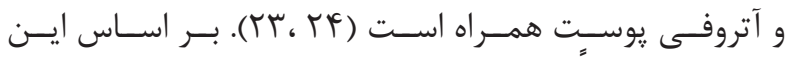

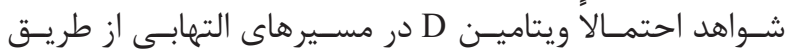

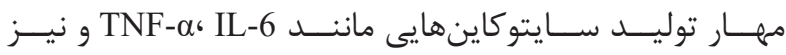

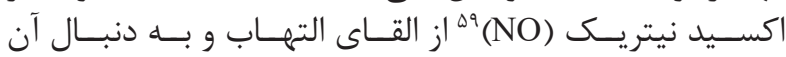
از بيــن رفتـن ســلول هاى عصبــى جلو كيــرى مى كنـــ (لهأ).

$$
\text { كمبود ويتامين D واثر آن بر فرايند اتوفازى }
$$

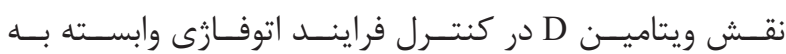

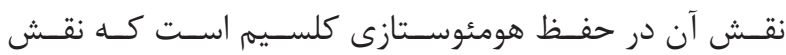

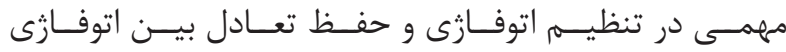

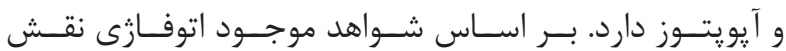

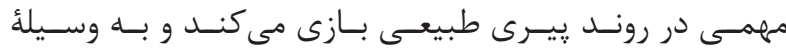

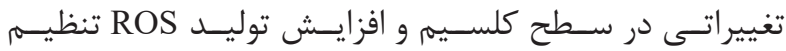

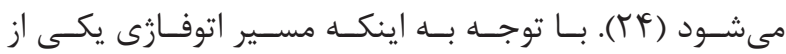

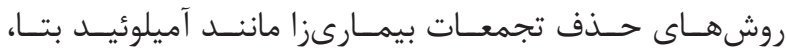

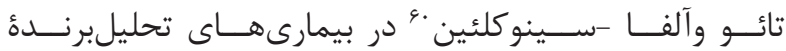

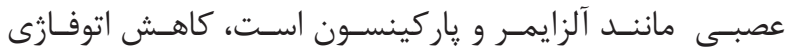

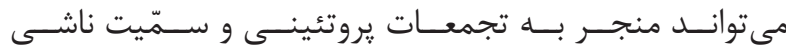

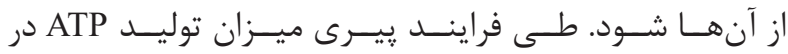

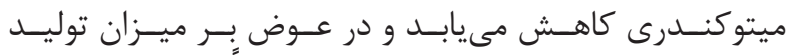

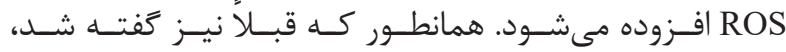

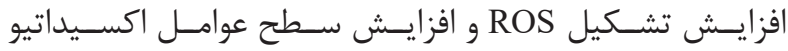

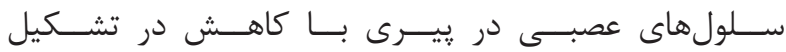

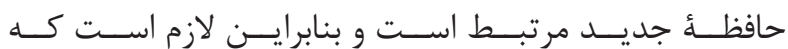

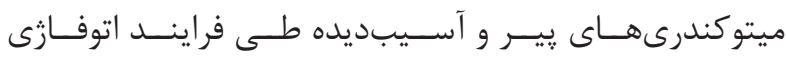

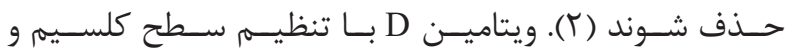

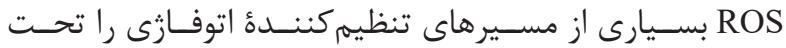

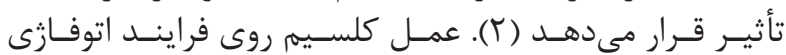

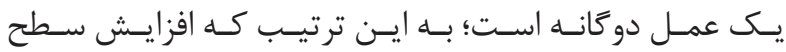

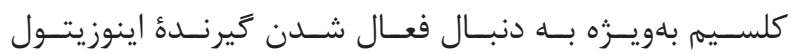

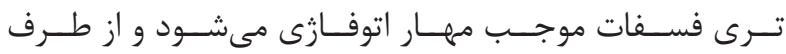

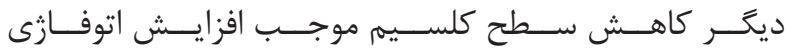

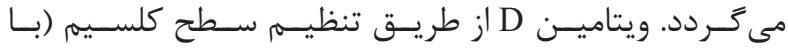

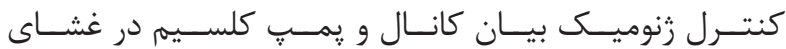

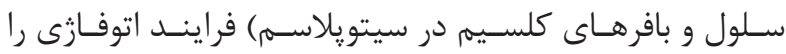

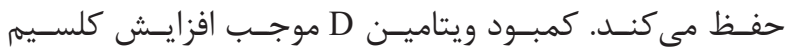

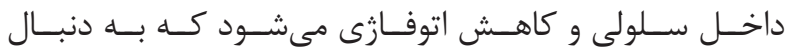

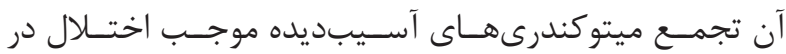

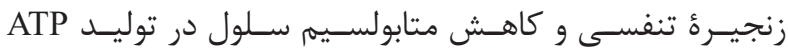

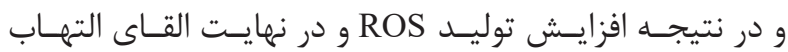

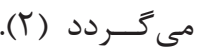

شـــواهدى وجــود دارد كـــهـ بــا افزايــش ســن، ســلولهاى

${ }^{54}$ Toll like receptor

${ }^{55}$ NADPH oxidase

${ }^{56} \mathrm{Kelch}-$ like ECH- associated protein 1

${ }^{57}$ Wingless/integrated

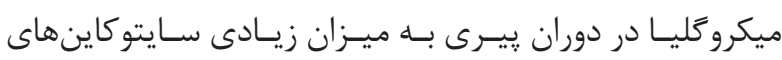

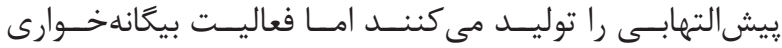

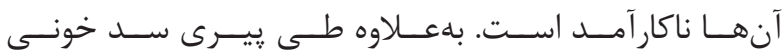

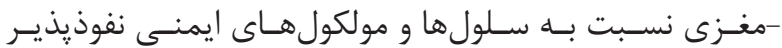

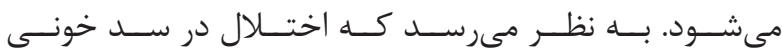

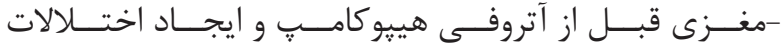

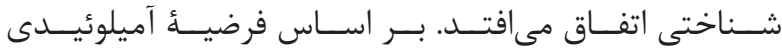

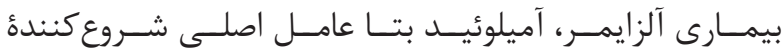

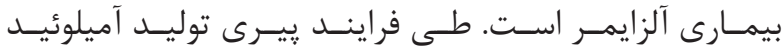

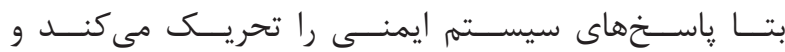

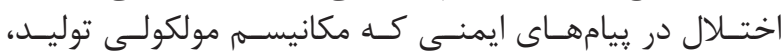

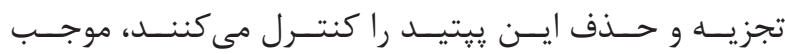

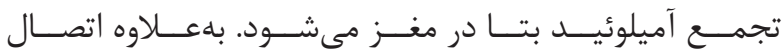

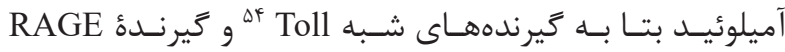

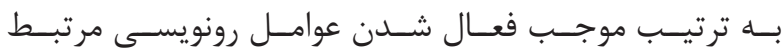

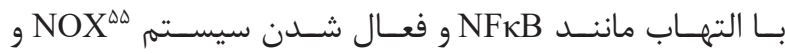

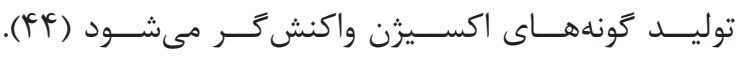

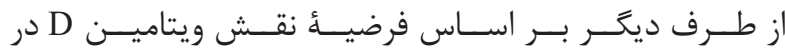

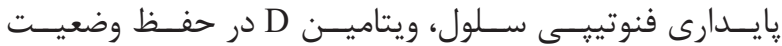

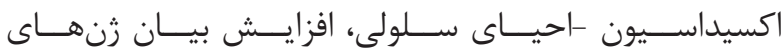

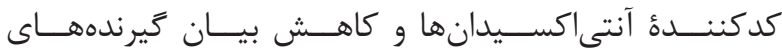

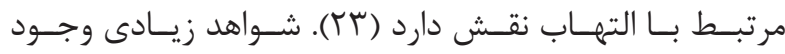

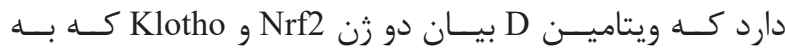

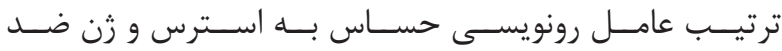

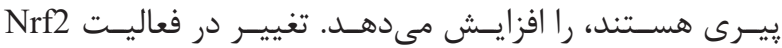

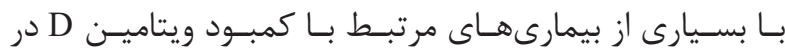

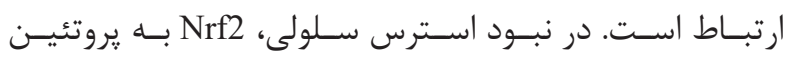

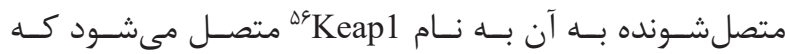

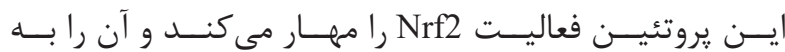

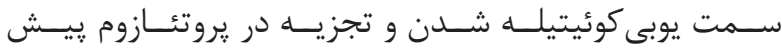

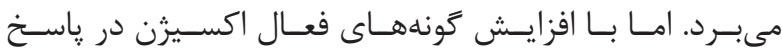

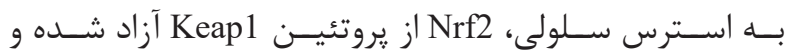

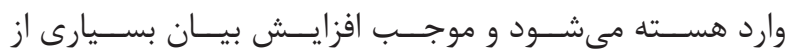

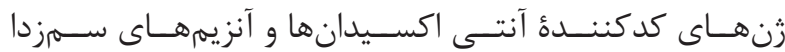

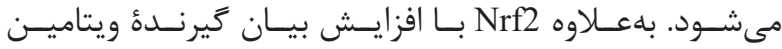

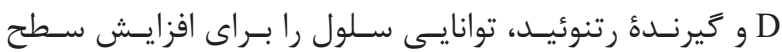

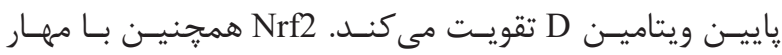

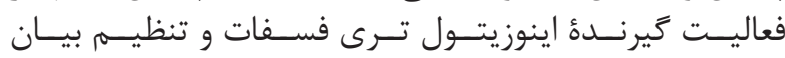
BCL2

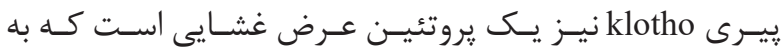

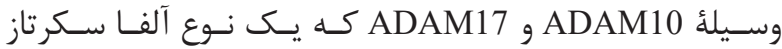

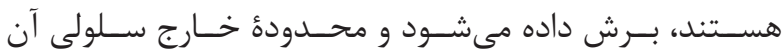

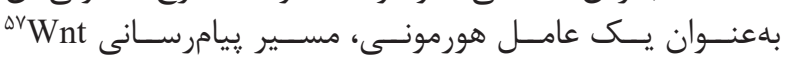

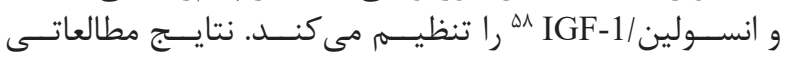

\footnotetext{
${ }^{58}$ Insulin-like growth factor 1

${ }^{59}$ Nitric oxide

${ }^{60} \alpha$-Synuclein
} 


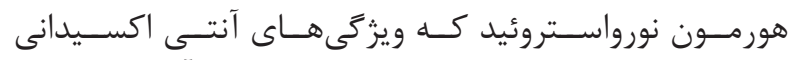

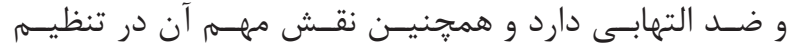

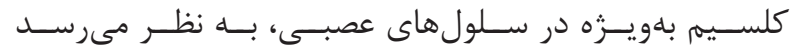

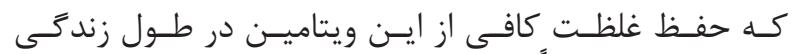

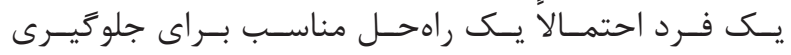

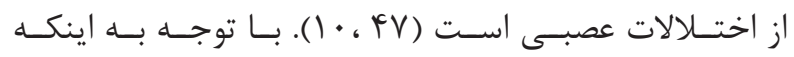

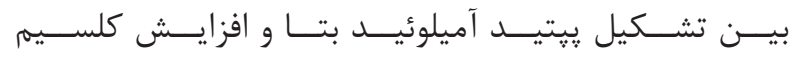

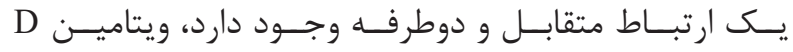

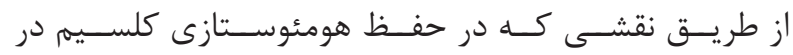

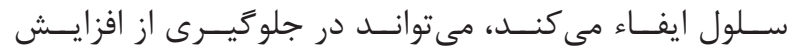

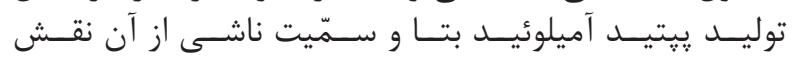

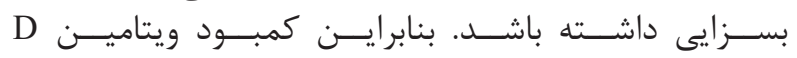

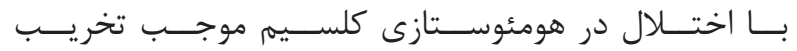

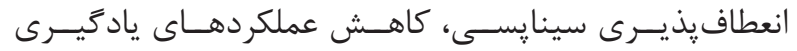

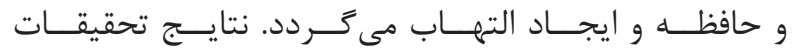

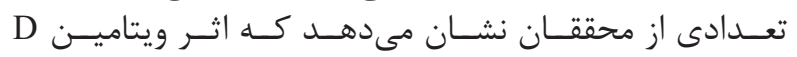

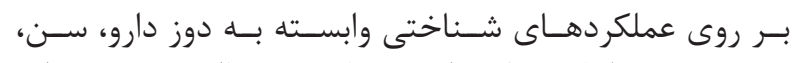

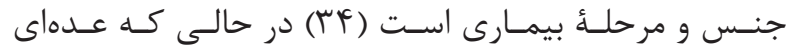

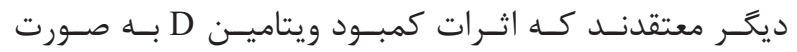

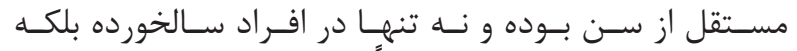

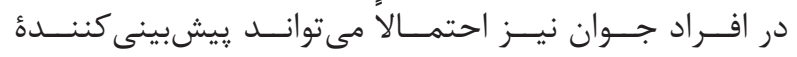

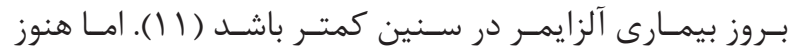

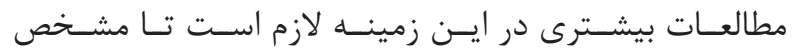

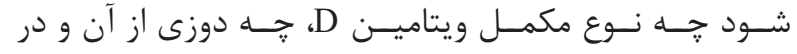

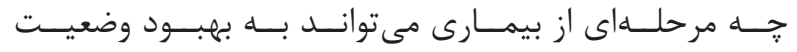

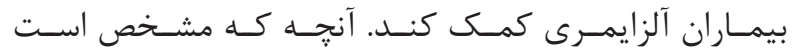

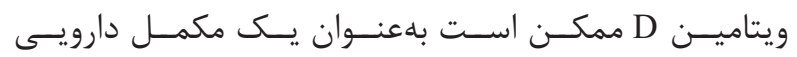

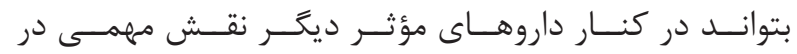

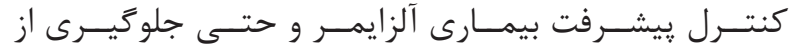

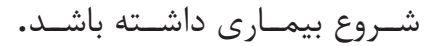

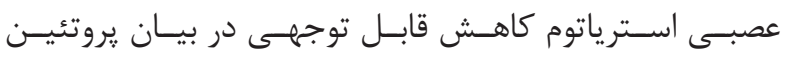

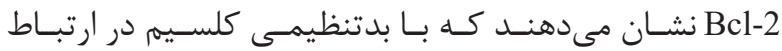

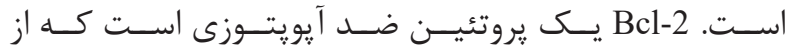

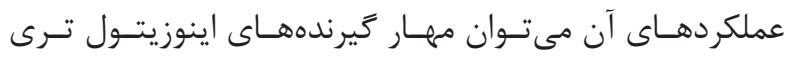

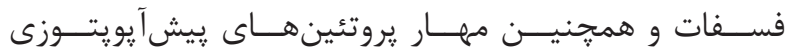

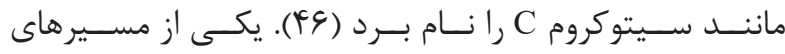

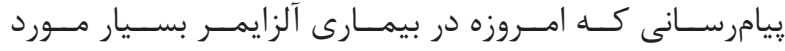

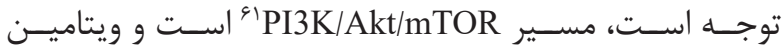

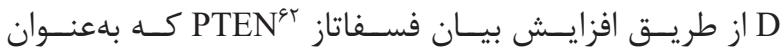

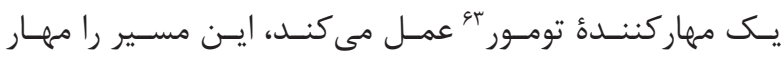

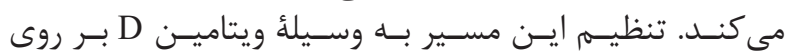

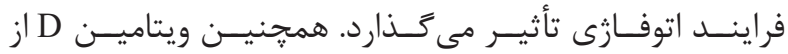

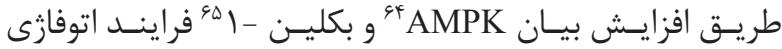

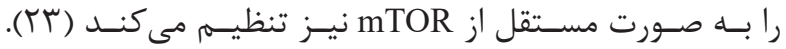

$$
\text { نتيجه گيرى }
$$

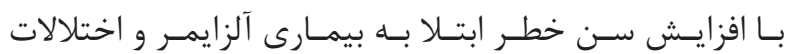

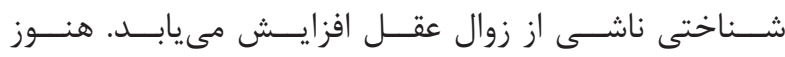

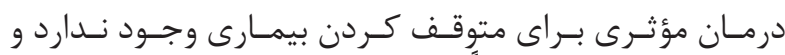

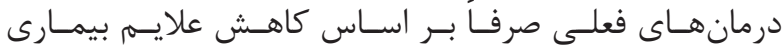

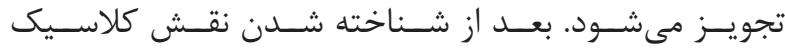

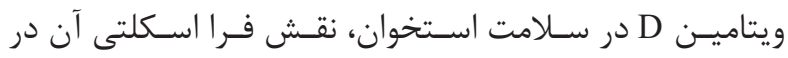

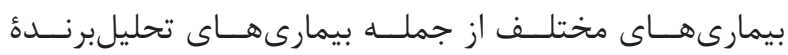

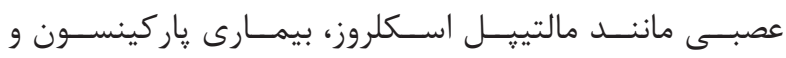

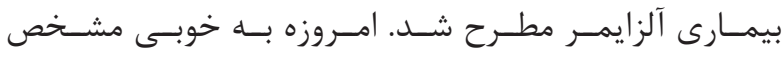

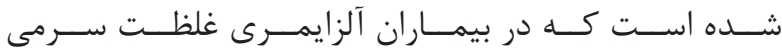

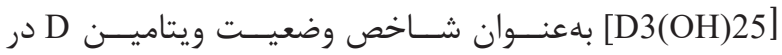

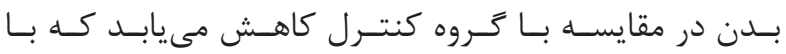

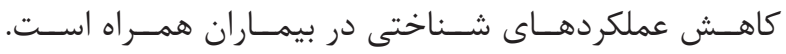

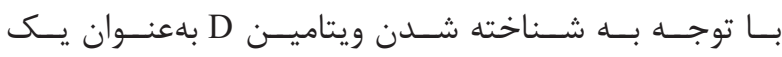

\footnotetext{
${ }^{61}$ Mammalian target of rapamycin

${ }^{62}$ Phosphatase and tensin homolog

${ }^{63}$ Tumor suppressor

${ }^{64}$ AMP- activated protein kinase

${ }^{65}$ Beclin-1
} 
1. Dusso AS, Brown AJ, Slatopolsky E. Vitamin D. American Journal of physiology Renal Physiology. 2005; 289(1): F8-28.

2. Berridge MJ. Vitamin D, reactive oxygen species and calcium signalling in ageing and disease. Philos Trans R Soc Lond B Biol Sci. 2016; 371 (1700): doi: 10.1098/rs tb.2015.0434.

3. Holick MF. The vitamin D deficiency pandemic: Approaches for diagnosis, treatment and prevention. Rev Endocr Metab Disord. 2017; 18(2): 153-65.

4. Bivona G, Agnello L, Bellia C, Iacolino G, Scazzone C, Lo Sasso B, et al. Non-skeletal activities of vitamin d: from physiology to brain pathology. Medicina (Kaunas). 2019; 55(7): 341. doi: 10.3390/medicina55070341.

5. van Schoor NM, Lips P. Worldwide vitamin D status. Best Pract Res Clin Endocrinol Metab. 2011; 25(4): 671-80.

6. Reitz C, Brayne C, Mayeux R. Epidemiology of Alzheimer disease. Cold Spring Harb Perspect Med. 2012; 2(8): doi: 10.1101/cshperspect.a006239.

7. Crews L, Masliah E. Molecular mechanisms of neurodegeneration in Alzheimer's disease. Hum Mol Genet. 2010; 19 (R1): R12-20.

8. Dursun E, Gezen-Ak D. Vitamin D basis of Alzheimer's disease: from genetics to biomarkers. Hormones. 2019; 18(1): 7-15.

9. Hill TR, Granic A, Aspray TJ. Vitamin D and ageing. Sub-Cellular Biochemistry. 2018; 90: 191-220.

10. Annweiler C, Brugg B, Peyrin JM, Bartha R, Beauchet $\mathrm{O}$. Combination of memantine and vitamin $\mathrm{D}$ prevents axon degeneration induced by amyloid-beta and glutamate. Neurobiol Aging. 2014; 35(2): 331-5.

11. Littlejohns TJ, Henley WE, Lang IA, Annweiler C, Beauchet O, Chaves PHM, et al. Vitamin D and the risk of dementia and Alzheimer disease. Neurology. 2014; 83(10): 920-8.

12. Chen H, Xue W, Li J, Fu K, Shi H, Zhang B, et al. 25-hydroxyvitamin $\mathrm{D}$ levels and the risk of dementia and Alzheimer's disease: A dose-response meta-analysis. Front Aging Neurosci. 2018; 10: 368.

13. Fleet JC. The role of vitamin D in the endocrinology controlling calcium homeostasis. Mol Cell Endocrinol. 2017; 453: 36-45.

14. Annweiler C, Rolland Y, Schott AM, Blain H,
Vellas B, Beauchet O. Serum vitamin predictor of incident non-Alzheimer dementias: a 7-yea longitudinal study. Dement Geriatr Cogn Disord. 2011; 32(4): $273-8$.

15. Christakos S, Dhawan P, Verstuyf A, Verlinden L, Carmeliet G. Vitamin D: metabolism, molecular mechanism of action, and pleiotropic effects. Physiol Rev. 2016; 96(1): 365-408.

16. Lips P. Vitamin D physiology. Prog Biophys Mol Biol. 2006; 92(1): 4-8.

17. Haussler MR, Whitfield GK, Kaneko I, Haussler CA, Hsieh D, Hsieh JC, et al. Molecular mechanisms of vitamin D action. Calcif Tissue Int. 2013; 92(2): 77-98.

18. Medrano M, Carrillo-Cruz E, Montero I, PerezSimon JA. Vitamin D: effect on haematopoiesis and immune system and clinical applications. Int J Mol Sci. 2018; 19(9): 2663. doi: 10.3390/ijms19092663.

19. Cashman KD, van den Heuvel EG, Schoemaker RJ, Preveraud DP, Macdonald HM, Arcot J. 25-hydroxyvitamin D as a biomarker of vitamin D status and its modeling to inform strategies for prevention of vitamin D deficiency within the population. Adv Nutr. 2017; 8(6): 947-57.

20. Institute of Medicine. Dietary reference intakes for calcium and vitamin D. Washington, DC: The National Academies Press; 2011.

21. Wang Y, Zhu J, DeLuca HF. Where is the vitamin D receptor? Arch Biochem Biophys. 2012; 523(1): 123-33.

22. McGrath J, Feron F, Eyles D, Mackay-Sim A. Vitamin D: the neglected neurosteroid? Trends in Neurosciences. 2001; 24(10): 570-2.

23. Berridge MJ. Vitamin D cell signalling in health and disease. Biochem Biophys Res Commun. 2015; 460(1): 53-71.

24. Berridge MJ. Vitamin D deficiency accelerates ageing and age-related diseases: a novel hypothesis. J Physiol. 2017; 595 (22): 6825-36.

25. Chen J, Olivares-Navarrete R, Wang Y, Herman TR, Boyan BD, Schwartz Z. Protein-disulfide isomeraseassociated 3 (Pdia3) mediates the membrane response to 1,25-dihydroxyvitamin D3 in osteoblasts. J Biol Chem. 2010; 285(47): 37041-50.

26. Falkenstein E, Tillmann HC, Christ M, Feuring M, Wehling M. Multiple actions of steroid hormones--a focus on rapid, nongenomic effects. Pharmacological 
Reviews. 2000; 52(4): 513-56.

27. Cui X, Gooch H, Petty A, McGrath JJ, Eyles D. Vitamin D and the brain: Genomic and non-genomic actions. Mol Cell Endocrinol. 2017; 453: 131-43.

28. Baeke F, Takiishi T, Korf H, Gysemans C, Mathieu C. Vitamin D: modulator of the immune system. Curr Opin Pharmacol. 2010; 10(4): 482-96.

29. Eyles DW, Smith S, Kinobe R, Hewison M, McGrath JJ. Distribution of the vitamin D receptor and 1 alphahydroxylase in human brain. J Chem Neuroanat. 2005; 29(1): 21-30.

30. Balabanova S, Richter HP, Antoniadis G, Homoki J, Kremmer N, Hanle J, et al. 25-Hydroxyvitamin D, 24, 25-dihydroxyvitamin D and 1,25-dihydroxyvitamin D in human cerebrospinal fluid. Klin Wochenschr. 1984; 62(22): 1086-90.

31. Wrzosek M, Lukaszkiewicz J, Wrzosek M, Jakubczyk A, Matsumoto H, Piatkiewicz P, et al. Vitamin D and the central nervous system. Pharmacol Rep. 2013; 65(2): 271-8.

32. Eyles D, Brown J, Mackay-Sim A, McGrath J, Feron F. Vitamin D3 and brain development. Neuroscience. 2003; 118(3): 641-53.

33. Groves NJ, McGrath JJ, Burne TH. Vitamin D as a neurosteroid affecting the developing and adult brain. Annu Rev Nutr. 2014; 34: 117-41.

34. Morello M, Landel V, Lacassagne E, Baranger $\mathrm{K}$, Annweiler C, Feron F, et al. Vitamin D improves neurogenesis and cognition in a mouse model of Alzheimer's disease. Mol Neurobiol. 2018; 55(8): 646379.

35. Miller BJ, Whisner CM, Johnston CS. Vitamin D supplementation appears to increase plasma abeta40 in vitamin D insufficient older adults: a pilot randomized controlled trial. J Alzheimers Dis. 2016; 52(3): 843-7.

36. Khaledi S, Ahmadi S. Amyloid beta and tau: from physiology to pathology in Alzheimer's disease. Shefaye Khatam. 2016; 4(4): 67-88.

37. Keisala T, Minasyan A, Lou YR, Zou J, Kalueff AV,
Pyykko I, et al. Premature aging in vitamin D receptor mutant mice. J Steroid Biochem Mol Biol. 2009; 115(35): 91-7.

38. Oliveira AM, Bading H, Mauceri D. Dysfunction of neuronal calcium signaling in aging and disease. Cell Tissue Res. 2014; 357(2): 381-3.

39. Brawek B, Garaschuk O. Network-wide dysregulation of calcium homeostasis in Alzheimer's disease. Cell Tissue Res. 2014; 357(2): 427-38.

40. Wang Y, Shi Y, Wei H. Calcium dysregulation in Alzheimer's disease: A target for new drug development. J Alzheimers Dis Parkinsonism. 2017; 7 (5): 374. doi: 10.4172/2161-0460.1000374.

41. Ahmadi S, Zobeiri M, Bradburn S. Molecular mechanisms underlying actions of certain long noncoding RNAs in Alzheimer's disease. Metab Brain Dis. 2020; 35(5): 681-93.

42. Koduah P, Paul F, Dorr JM. Vitamin D in the prevention, prediction and treatment of neurodegenerative and neuroinflammatory diseases. EPMA J. 2017; 8(4): 313-25.

43. Mayne PE, Burne THJ. Vitamin D in synaptic plas ticity, cognitive function, and neuropsychiatric illness. Trends Neurosci. 2019; 42(4): 293-306.

44. Newcombe EA, Camats-Perna J, Silva ML, Valmas N, Huat TJ, Medeiros R. Inflammation: the link between comorbidities, genetics, and Alzheimer's disease. J Neuroinflammation. 2018; 15 (1): 276. doi: 10.1186/ s12974-018-1313-3.

45. Anas tasiou CA, Yannakoulia M, Scarmeas N. Vitamin D and cognition: an update of the current evidence. J Alzheimers Dis. 2014; 42(3): S71-80.

46. Rong Y, Distelhorst CW. Bcl-2 protein family members: versatile regulators of calcium signaling in cell survival and apoptosis. Annu Rev Physiol. 2008; 70: 73-91.

47. Annweiler C. Vitamin D in dementia prevention. Annals of the New York Academy of Sciences. 2016; 1367(1): 57-63. 